\title{
Anhanguera taxonomy revisited: is our understanding of Santana Group pterosaur diversity biased by poor biological and stratigraphic control?
}

\author{
Felipe L Pinheiro ${ }^{\text {Corresp., }}{ }^{1}$, Taissa Rodrigues ${ }^{2}$ \\ 1 Laboratório de Paleobiologia, Universidade Federal do Pampa, São Gabriel, RS, Brazil \\ 2 Departamento de Ciências Biológicas, Universidade Federal do Espírito Santo, Vitória, ES, Brazil \\ Corresponding Author: Felipe L Pinheiro \\ Email address: felipepinheiro@unipampa.edu.br
}

Background. Anhanguerids comprise an important clade of pterosaurs, mostly known from dozens of three-dimensionally preserved specimens recovered from the Lower Cretaceous Romualdo Formation (northeastern Brazil). They are remarkably diverse in this sedimentary unit, with eight named species, six of them belonging to the genus Anhanguera. However, such diversity is likely overestimated, as these species have been historically diagnosed based on subtle differences, mainly based on the shape and position of the cranial crest. In spite of that, recently discovered pterosaur taxa represented by large numbers of individuals, including juveniles and adults, as well as presumed males and females, have crests of sizes and shapes that are either ontogenetically variable or sexually dimorphic.

Methods. We describe in detail the skull of one of the most complete specimen referred to Anhanguera, AMNH 22555, and use it as a case study to review the diversity of anhanguerids from the Romualdo Formation. In order to accomplish that, a geometric morphometric analysis was performed to assess sizedependent characters with respect to the premaxillary crest in the 12 most complete skulls bearing crests that are referred in, or related to, this clade, almost all of them analyzed first hand.

Results. Geometric morphometric regression of shape on centroid size was highly statistically significant ( $p=0.0091$ ) and showed that allometry accounts for $25.7 \%$ of total shape variation between skulls of different centroid sizes. Premaxillary crests are both taller and anteroposteriorly longer in larger skulls, a feature consistent with ontogenetic growth. A new diagnosis is proposed for Anhanguera, including traits that are nowadays known to be widespread within the genus, as well as ontogenetic changes. AMNH 22555 cannot be referred to "Anhanguera santanae" and, in fact, "Anhanguera santanae", "Anhanguera araripensis", and "Anhanguera robustus" are here considered nomina dubia.

Discussion. Historically, minor differences in crest morphology have been used in the definition of new anhanguerid species. Nowadays, this practice resulted in a considerable difficulty in referring wellpreserved skulls into known taxa. When several specimens are analyzed, morphologies previously believed to be disparate are, in fact, separated by a continuum, and are thus better explained as individual or temporal variations. Stratigraphically controlled excavations on the Romualdo Formation have showed evidence for faunal turnover regarding fish communities. It is thus possible that some of the pterosaurs from this unit were not coeval, and might even represent anagenetic morphotypes. Unfortunately, amateur collecting of Romualdo Formation fossils, aimed especially at commerce, resulted in the lack of stratigraphic data of virtually all its pterosaurs and precludes testing of these further hypotheses. 
1 Anhanguera taxonomy revisited: is our understanding of Santana Group pterosaur

2 diversity biased by poor biological and stratigraphic control?

3 Felipe L. Pinheiro ${ }^{1 *}$, Taissa Rodrigues ${ }^{2}$

4 1. Laboratório de Paleobiologia, Universidade Federal do Pampa, São Gabriel, RS, Brazil; 2.

5 Departamento de Ciências Biológicas, Centro de Ciências Humanas e Naturais, Universidade

6 Federal do Espírito Santo, Vitória, ES, Brazil.

7 *Corresponding author, felipepinheiro@unipampa.edu.br

8 Abstract

9 Background. Anhanguerids comprise an important clade of pterosaurs, mostly known from dozens of three-dimensionally preserved specimens recovered from the Lower Cretaceous Romualdo Formation (northeastern Brazil). They are remarkably diverse in this sedimentary unit, with eight named species, six of them belonging to the genus Anhanguera. However, such diversity is likely overestimated, as these species have been historically diagnosed based on subtle differences, mainly based on the shape and position of the cranial crest. In spite of that, recently discovered pterosaur taxa represented by large numbers of individuals, including juveniles and adults, as well as presumed males and females, have crests of sizes and shapes that are either ontogenetically variable or sexually dimorphic.

Methods. We describe in detail the skull of one of the most complete specimen referred to Anhanguera, AMNH 22555, and use it as a case study to review the diversity of anhanguerids from the Romualdo Formation. In order to accomplish that, a geometric morphometric analysis was performed to assess size-dependent characters with respect to the premaxillary crest in the 12 most complete skulls bearing crests that are referred in, or related to, this clade, almost all of them analyzed first hand.

Results. Geometric morphometric regression of shape on centroid size was highly statistically significant $(\mathrm{p}=0.0091)$ and showed that allometry accounts for $25.7 \%$ of total shape variation between skulls of different centroid sizes. Premaxillary crests are both taller and anteroposteriorly longer in larger skulls, a feature consistent with ontogenetic growth. A new diagnosis is proposed for Anhanguera, including traits that are nowadays known to be 
widespread within the genus, as well as ontogenetic changes. AMNH 22555 cannot be referred to "Anhanguera santanae" and, in fact, "Anhanguera santanae", "Anhanguera araripensis", and “Anhanguera robustus" are here considered nomina dubia.

Discussion. Historically, minor differences in crest morphology have been used in the definition of new anhanguerid species. Nowadays, this practice resulted in a considerable difficulty in referring well-preserved skulls into known taxa. When several specimens are analyzed, morphologies previously believed to be disparate are, in fact, separated by a continuum, and are thus better explained as individual or temporal variations. Stratigraphically controlled excavations in the Romualdo Formation have showed evidence for faunal turnover regarding fish communities. It is thus possible that some of the pterosaurs from this unit were not coeval, and might even represent anagenetic morphotypes. Unfortunately, amateur collecting of fossils in the Romualdo Formation, aimed especially at commerce, resulted in the lack of stratigraphic data for virtually all its pterosaurs and precludes testing of these further hypotheses.

\section{Introduction}

Anhangueridae is a clade of pterosaurs currently known from multiple localities worldwide, including named species from Brazil, the United States, Morocco, China and England (Rodrigues \& Kellner, 2013). The majority of identifiable material comes from the Romualdo Formation (Araripe Basin, northeastern Brazil), a well-known fossil Lagerstätte where they are the most abundant and speciose clade of tetrapods, with eight named species (Tropeognathus mesembrinus, Maaradactylus kellneri and six species of Anhanguera) (Table 1), as well as several closely-related pterosaur taxa and dozens of referred specimens. Even though this anhanguerid taxonomy has already been disputed by several authors (Kellner \& Tomida, 2000; Fastnacht, 2001; Unwin, 2001; Veldmeijer, 2003), the apparent species diversity seems nonetheless remarkable.

Although the first descriptions of pterosaurs from the Romualdo Formation date from as early as the 1970s (Price, 1971), well-preserved skull material only began to be described in the 1980s and 1990s. In February 1985, Wellnhofer described a number of specimens from the Romualdo Formation, naming two new species based on fossils comprising skull material: 
58

59

60

61

62

63

64

65

66

67

68

69

"Santanadactylus" araripensis and "Araripesaurus" santanae; both genera were previously described based only on postcranial material. Later that same year, Campos and Kellner described the new genus and species Anhanguera blittersdorffi, based on a complete skull. In 1987, Wellnhofer described two further species, Tropeognathus mesembrinus and "Tropeognathus robustus". With increasing knowledge of these Romualdo Formation anhanguerids, some new taxonomic proposals arose, including placing all of these species in the genus Anhanguera (Kellner, 1990).

Additional anhanguerid specimens, but no newly named species, were subsequently described by Wellnhofer (1991); among them AMNH 22555 is an incomplete skeleton including a skull and a fragmentary mandible. It was the most complete skeleton then known from the Romualdo Formation, and served as the basis for the first anhanguerid skeleton reconstruction ever made (Wellnhofer, 1991). This specimen was regarded by Wellnhofer (1991) as conspecific with the holotype of "Anhanguera santanae" (previously in the genus "Araripesaurus"). Remarkably, two other almost complete skeletons, including skulls, were later described and referred to the species Anhanguera piscator (Kellner \& Tomida, 2000) and "Coloborhynchus" spielbergi (Veldmeijer, 2003).

Today, several skulls (both described and undescribed) are hosted in a myriad of publically accessible collections and thus enabling the examination of a larger sample of Romualdo anhanguerids (Table 2). Recent proposals (Kellner \& Tomida, 2000; Rodrigues \& Kellner, 2008) referred the species A. blittersdorffi, "A. araripensis", “A. santanae”, "A. robustus”, A. piscator and A. spielbergi to the genus Anhanguera. These taxa are mostly diagnosed by subtle differences in cranial anatomy, mainly focused on the morphology and position of the cranial crest, a character that is presumably sexually dimorphic and/or ontogenically variable (Bennett, 1992, Manzig et al., 2014, Wang et al., 2014). The supposedly diagnostic features of individual Anhanguera species are so discreet and ambiguous that it is virtually impossible to attribute new material to any of the proposed existing taxa with any level of certainty, which also indicates a probable artificial inflation of the diversity of species within the genus. This issue is due to our relatively poor understanding of intraspecific variation in Anhanguera, and which characters might vary according to differences in sex and ontogeny. 
87 Here we reanalyze the skull of the specimen AMNH 22555, originally referred to "Anhanguera santanae" by Wellnhofer (1991), an assumption that was thereafter echoed by other authors (e.g. Kellner \& Tomida, 2000; Veldmeijer, 2003). A new description is justified by the fact that Wellnhofer (1991), assuming that AMNH 22555 was not significantly different from " $A$. santanae" holotype, only devoted one paragraph for the skull in its original description. The new description of AMNH 22555 presented here is used as the basis to explore possible reasons behind the problematic taxonomy of Anhanguera. We apply a geometric morphometric approach to establish size-dependent characters within Anhanguera-like pterosaurs, and make a reassessment of the putative diagnostic features of each of the proposed Anhanguera species, resulting in a revised taxonomy for the genus. We also discuss the possibility that our poor understanding of Romualdo stratigraphy is undermining our wider knowledge of Santana Group pterosaur diversity, by occluding a putative connection between different Anhanguera morphotypes and temporally distinct fossil-bearing strata.

\section{Institutional abbreviations}

AMNH - American Museum of Natural History, New York, USA

MHNS - Museu de História Natural de Sintra, Sintra, Portugal

MN - Museu Nacional / Universidade Federal do Rio de Janeiro, Rio de Janeiro, Brazil

MPSC - Museu de Paleontologia, Santana do Cariri, Brazil

NHMUK - Natural History Museum, London, UK

NSM - National Science Museum, Tokyo, Japan

DBAV-UERJ - Universidade do Estado do Rio de Janeiro, Rio de Janeiro, Brazil

RGM - National Natuurhistorisch Museum / Naturalis, Leiden, The Netherlands

SAO - Sammlung Oberli, a private collection belonging to Mr. Urs Oberli, Sankt Gallen, Switzerland

SMNK - Staatliches Museum für Naturkunde, Karlsruhe, Germany 
113 SNSB-BSPG - Staatliche Naturwissenschaftliche Sammlungen Bayerns / Bayerische

114 Staatssammlung für Paläontologie und Geologie, Munich, Germany

115

116 Materials and Methods

117 Geological setting

118 All the specimens up until now assigned to the genus Anhanguera have come from the

119 Romualdo Formation (Albian) of the Araripe Basin, northeastern Brazil (Figure 1). The

120 Romualdo Formation is characterized by conglomeratic sandstones overlain by a transgressive

121 sequence of green and black shales (Assine, 2007). Within the black shales, the presence of

122 several layers rich in carbonate concretions is apparent, and with lateral continuity throughout

123 the basin (Fara et al., 2005; Saraiva et al., 2007; Vila Nova et al., 2011). The genesis of these

124 layers is associated with mass mortality events, followed by the formation of early diagenetic

125 concretions that entrapped a large number of elements of the Romualdo biota.

\section{Studied material}

128 In order to assess the biological and stratigraphic biases that may have impacted on the taxonomy of Anhanguera, we reevaluated the specimen AMNH 22555 (commonly referred as “Anhanguera santanae” Figure 2) through a comprehensive cranial description. Although this particular specimen has often been mentioned and illustrated in specialized literature (e.g. Wellnhofer, 1991; Kellner \& Tomida, 2000), a detailed description is still pending and, as will be demonstrated, its attribution to "Anhanguera santanae" is mainly based on a superficial resemblance. AMNH 22555 is a partial pterosaur skeleton, composed of an almost complete skull, proximal end of the right mandibular ramus (Figure 2, F, G), nearly all vertebral elements (Figure 2, A-E), some ribs, scapulae and coracoids (Figure 2, H, I), an almost complete pelvis and some limb elements, including carpals (Figure 2, J, K), metacarpals, femoral and humeral fragments, incomplete radius and ulna, pteroid, and foot phalanges (Figure 2). With the sole exception of Anhanguera piscator (which was accessed through the cast MN 5023-V) and Maaradactylus kellneri (holotype MPSC R 2357), all other specimens here used for comparison and allometric regressions were examined first hand by the authors. 
144 In order to assess size-dependent characters within Anhanguera-like pterodactyloids, we used geometric morphometrics in a series of 12 skulls attributed to Anhanguera and closely-related taxa (Anhangueria sensu Rodrigues and Kellner, 2013), namely: Anhanguera blittersdorffi (holotype, MN 4805-V), Anhanguera piscator (holotype, NSM-PV 19892), Anhanguera spielbergi (holotype, RGM 401 880), Anhanguera sp. (NHMUK R 11978), Anhanguera sp. (SAO 16494), Anhanguera sp. (SMNK PAL 1136), Anhanguera sp. (MN 4735-V, referred to “Anhanguera araripensis” by Kellner and Tomida, 2000), SMNK PAL 3895 (referred to Cearadactylus atrox by Campos, Headden \& Frey, 2013), Barbosania gracilirostris (holotype, MHNS/00/85), Maaradactylus kellneri (holotype, MPSC R 2357, based on the reconstruction provided by Bantim et al., 2014), Tropeognathus mesembrinus (holotype, SNSB-BSPG 1987 I 46) and Tropeognathus cf. T. mesembrinus (MN 6594-V, based on the reconstruction provided by Kellner et al., 2013). “Anhanguera santanae” (holotype, SNSB-BSPG 1982 I 90), AMNH 22555 (referred to "Anhanguera santanae" by Wellnhofer, 1991), and "Anhanguera araripensis" (holotype, SNSB-BSPG 1982 I 89) were not included because the crest is not preserved in these specimens.

159

160

161

162

163

164

165

166

167

168

169

170

171

Two-dimensional coordinates were captured for 17 landmarks using digital photographs of specimens in lateral aspect and the software TPSDig (Rohlf, 2010). Landmarks were chosen as follow: 1, posteriormost edge of squamosal; 2, dorsalmost edge of the frontoparietal crest; 3 , contact between prefrontal and supraorbital, at the dorsal margin of the orbit; 4 , contact between jugal and lacrimal; 5, posterior limit of the lateral shelf of the jugal, at the base of the ascending process of this bone; 6 , contact between frontoparietal and postorbital, at the posterior margin of the orbit; 7, ventral edge of the quadrate; 8 , anterior limit of the lateral shelf of the jugal, at the base of the ascending process of this bone; 9, contact between lacrimal and nasal, at the dorsal margin of the nasoantorbital fenestra; 10, contact between premaxilla and maxilla, at the anterior margin of the nasoantorbital fenestra; 11, posterior extension of the premaxillary crest; 12 , dorsalmost extension of the premaxillary crest; 13, mid-length between landmarks 11 and 12, as projected on the dorsal margin of the premaxillary crest; 14, anterior extension of the premaxillary crest; 15, mid-length between landmarks 12 and 14, as projected on the dorsal 
172 margin of the premaxillary crest; 16, anterior tip of the rostrum; 17, mid-length between

173 landmarks 7 and 16, as projected on the ventral margin of the maxilla (Figure 3).

174 The main goal of our analyses was to detect and describe morphologic variation attributable to

175 the increase of skull size, especially with respect to the premaxillary crest. Although our study is

176 mainly focused on the genus Anhanguera, the inclusion of closely-related taxa bearing

177 premaxillary ornaments was justified by the assumption that homologous structures in

178 phylogenetically related animals probably shared functions and growth patterns. All analyses

179 were carried out using the MorphoJ software package, version 1.06a (Klingenberg, 2011). The

180 allometric regression included centroid size as a proxy for cranial size (independent variable) and

181 the shape score $s$ proposed by Drake and Klingenberg (2008) (dependent variable), which

182 includes shape changes predicted by allometry, as well as residual variations that are not

183 dependent to size. The MorphoJ algorithm allowed us to then identify morphological changes

184 entirely related to allometry from the residual variations. A permutation test against the null

185 hypothesis of independence was made in order to test the sensitivity of the regression analyses

186 (10,000 rounds).

187 As the landmark plotting for Maaradactylus kellneri (MPSC R 2357) and Tropeognathus cf. $T$.

188 mesembrinus (MN 6594-V) was based on tentative reconstructions provided in the literature,

189 respectively by Bantim et al. (2014) and Kellner et al. (2013), a second regression analysis with

190 the exclusion of those specimens was also performed.

191 Bantim et al. (2015) also carried out allometric regressions in order to investigate cranial crest

192 development within Anhangueridae. These authors, however, used a limited sample of six

193 specimens and restricted their analyses to linear values of crest length and height in order to

194 assess morphology.

195

196 Results

197 Allometric regressions

198 Our first analysis, including the whole sample of 12 skulls attributed to Anhanguera and closely 199 related taxa, detected a highly statistically significant $(p=0.0091)$ regression of shape on 
200

201

202

203

204

205

206

207

208

209

210

211

212

213

214

215

216

217

218

219

220

221

222

223

224

225

226

227

228

229

centroid size. Allometry alone accounts for $25.7 \%$ of the total shape variation between skulls of different centroid sizes (Figure 3). The pattern of allometric growth shows a pronounced dorsal shift of landmarks associated to the premaxillary crest $(12,13$ and 15), demonstrating a clear trend of dorsal growth of this structure along with the increase in size. It is also evident that landmarks related to the posterior and anterior limits of the premaxillary crest are, respectively, posteriorly and anteriorly displaced in larger specimens (Figure 3). This pattern of anteroposterior growth of the crest means that larger specimens of Anhanguera-like pterosaurs tend to have premaxillary crests beginning closer to the nasoantorbital fenestra than smaller ones. The distance between the anterior extension of the nasoantorbital fenestra and the posterior end of the crest is also affected by the occurrence of a proportionally longer nasoantorbital fenestra in larger specimens. Also, the anterior end of the crest presents a positive trend of displacement towards the anterior tip of the rostrum in larger skulls. Notably, the orbits show negative allometric growth, with larger specimens bearing proportionally smaller orbits.

The second analysis, in which Maaradactylus kellneri (MPSC R 2357) and Tropeognathus cf. mesembrinus (MN 6594-V) were excluded, also demonstrates a strong relationship between centroid size and shape, with allometry accounting for $22.73 \%$ of total shape variation. This second regression was, however, less statistically significant $(p=0.058)$, but all of the morphological trends detected in the first analysis were still recovered.

We also analyzed the residual (uncorrelated with size) component of variation for each specimen, in an attempt to identify individual morphological disparity, which is potentially attributable to interspecific variation. At least two specimens indeed show a considerable amount of residual variation of shape, unpredicted by our regression model. Specimen MN 4735-V, attributed by Kellner and Tomida (2000) to "Anhanguera araripensis", for instance, has a much bigger premaxillary crest than what would be expected for an animal of its size class, while the Anhanguera piscator holotype (NSM-PV 19892) has a proportionally small crest for its size.

Notably, some of the residual variation observed in other specimens is attributable to diagenetic modification of fossils, such as an upward shift of the rostrum in NHMUK R 11978 and in the Maaradactylus kellneri holotype (MPSC R 2357). Most of the observed residual components of variation, however, are difficult to describe as discrete traits and seem to vary continuously on our sample, with disparate morphologies linked together by a set of intermediaries. 
The skull of AMNH 22555

232 Pterosauria Kaup, 1834

233 Pterodactyloidea Plieninger, 1901

234 Anhangueria Rodrigues and Kellner, 2013

235 Anhangueridae Campos and Kellner, 1985

236 Anhanguera Campos and Kellner, 1985

237 Anhanguera sp.

238 Locality and horizon. Romualdo Formation, Araripe Basin, Albian, northeastern Brazil.

239 According to Wellnhofer (1991), the specimen comes from Jardim municipality in the state of

240 Ceará (previously Barra do Jardim), but its exact locality is undetermined.

241 Anatomical description. The skull of AMNH 22555 is nearly complete and best preserved in

242 right lateral aspect (Figure 4, 5). Even so, rostral elements anterior to the nasoantorbital fenestrae

243 are crushed and laterally compressed in this view. Posterior skull bones are broken and

244 disarticulated in left lateral view, in which the absence of bones such as the left jugal and

245 lacrimal obliterates the edges of skull openings. The palate anterior to the choanae is well

246 preserved, whereas posterior palatal bones are mostly absent. Parts of the right pterygoid lie

247 inside the nasoantorbital opening in lateral view. Despite the fact that the alveolar margin of the

248 maxillae is intact anteriorly, with the presence of some in situ teeth (mostly broken) and empty

249 alveoli, the ventral margins of both the left and right maxillae are eroded and incomplete

250 posteriorly, preventing an accurate estimation of the total number of tooth positions. The

251 posterior skull roof is almost intact, with a slight lateral displacement of the frontoparietals.

252 Above the nasoantorbital openings, the outer bone layer of the dorsal margin of the fused

253 premaxillae is eroded. The dorsal limits of the premaxillae are badly crushed throughout the

254 anterior half of the skull, preventing the reconstruction of the sagittal crest anatomy. In occipital

255 view, only the broad supraoccipital plate and right opisthotic are fairly well preserved. 
256 In general, the skull bones are disarticulated and, sometimes, displaced from their original

257 positions. The premaxillae and maxillae, as well as the frontals and parietals, are tightly fused

258 with each other, displaying the ordinary condition for pterodactyloids. Some postcranial bones,

259 known to fuse in mature individuals, show the unfused condition in AMNH 22555, indicating

260 that this specimen is osteologically immature (Wellnhofer, 1991; Bennett, 1993). Those elements

261 include separate scapulae and coracoids, as well as proximal and distal carpals (Figure 2, H-K).

262 The first five dorsal vertebrae show very thick neural spines and prezygapophyses fused with the

263 postzygapophyses of the adjacent vertebra, indicating that a notarium was present in mature

264 individuals of this species (Figure 2, B).

265 Premaxilla. The fused premaxillae comprise most of the skull roof, with their posterior ends

266 dorsal to the orbits, where they contact the frontoparietals posteriorly. Although the left

267 premaxilla is considerably well preserved throughout its whole extension, the right element is

268 badly crushed anteriorly to the nasoantorbital fenestra. Sutures between the premaxillae and

269 maxillae can only be observed close to the nasoantorbital fenestrae, especially on the left side of

270 the skull (where this region is best preserved). Anteriorly, the ventral limits of the premaxillae

271 are not clear, and the number of tooth positions associated with these bones cannot be inferred.

272 The dorsal surface of the premaxillae is broken in the region anterior to the nasoantorbital

273 fenestrae, making it difficult to determine if a sagittal crest was present. However, this broken

274 dorsal border extends above the projection of the surface dorsal to the nasoantorbital openings,

275 which may indicate that the crest was present. It is probable that the premaxillae also composed

276 the anterior part of the palate, where the bone is strongly pierced by small foramina. However,

277 due to bone fusion, it is impossible to determine the exact contribution of the premaxillae to the

278 palatal surface. There is a discrete anterior expansion of the skull, with the rostrum being about

$279 \quad 1.5-2 \mathrm{~mm}$ wider at the level of the $4^{\text {th }}$ tooth sockets than at the $3^{\text {rd }}$ and $5^{\text {th }}$ alveoli. This is more

280 reminiscent of the slight expansion seen in Tropeognathus mesembrinus, but at this point it

281 cannot be ruled out that the expansion could grow larger with maturity.

282 Maxilla. Bordered dorsally by the premaxillae, the maxillae form the anterior and part of the

283 ventral margins of the nasoantorbital fenestrae. Because the suture lines between the maxillae

284 and premaxillae are located at the anterodorsal border of the nasoantorbital fenestrae, the

285 maxillae also make a small contribution to the dorsal margin of these openings. Ventrally, the 
286 palatal plates of the maxillae fuse together (see Ösi et al., 2010; Pinheiro \& Schultz, 2012),

287 forming a well-developed palatal ridge that ends about $50 \mathrm{~mm}$ before the anterior limits of the 288 choanae. The dental margins of the maxillae form strong rims, and some of the rostral teeth 289 (especially the $7^{\text {th }}$ to $10^{\text {th }}$ tooth pairs) are surrounded at their bases by robust bony collars, 290 generally punctured by foramina on their medial side. Because the jugal processes of both 291 maxillae are broken, the posterior limits of these bones cannot be determined. Anterior to the $9^{\text {th }}$

292 293

294 295 296 297 tooth pair, the ventral margins of the maxillae gently curve upwards, and the anteriormost teeth are inserted at level with the ventral margins of the orbits.

Nasal. Together with the lacrimals, the nasals form the posterodorsal margins of the nasoantorbital fenestrae. The right nasal is better preserved than the left one, and shows an irregular shape, with acute anterior and posterior extensions. The dorsal margin is straight and contacts the premaxillae. The nasals have lateral longitudinal ridges, probably indicating the contact area with the lacrimals (in AMNH 22555, these bones are slightly displaced). The nasals have concave posterior margins, fitting the convex prefrontals and supraorbitals. The ventral surfaces of the acute anterior processes of the nasals are perforated by well-developed foramina. The nasoantorbital openings are completely filled with carbonaceous matrix and, thus, the medial contact between the left and right nasals, as well as the ventral nasal process, are obscured.

Prefrontal. Only the right prefrontal is preserved. Dorsally, this bone makes contact with the nasal and the supraorbital, whereas ventrally it shows a rectilinear suture with the lacrimal. The prefrontal contributes to part of the anterodorsal margin of the orbit.

Supraorbital. Both supraorbitals are preserved. These bones are roughly triangular in dorsal aspect and compose part of the skull roof above the orbits. The contact between the supraorbitals and frontoparietals is marked by grooves, which are deeper at their posterior limits. The supraorbitals are also partially covered by the posterior extension of the premaxillae.

Frontoparietal. There is no visible distinction between the frontals and parietals, but a clear suture line divides the left and right elements of these bones. The frontoparietals form almost the entire skull roof above the orbits and the upper temporal fenestrae, being overlaid anteriorly by the slender posterior extension of the premaxillae that projects between the left and right frontoparietals. Above the upper temporal fenestrae, the dorsal margin of the frontoparietals 
315 forms a short crest that probably provided a greater area of origin for the musculus adductor

316 mandibulae externus.

317 Jugal. Only the right jugal is preserved. This is a robust element, mostly composed of three

318 strong processes that contribute to the boundaries of several skull openings. The maxillary

319 process of the jugal extends anteriorly, forming part of the posteroventral margin of the

320 nasoantorbital fenestra as well as it contributes to the lateral margin of the palatal subtemporal

321 fenestra. This process is broken in the preserved jugal of AMNH 22555, preventing an

322 estimation of how far anteriorly the contact with the maxillae was located. The lacrimal process

323 of the jugal is directed dorsally, with a slight anterior inclination, and forms part of the anterior

324 margin of the orbit, as well as part of the posterior margin of the nasoantorbital fenestra. The

325 spot where this process connects with the main corpus of the jugal is depressed, forming a

326 distinct lateral shelf, so that the whole process is medially displaced with respect to the

327 remainder of the bone. The contact with the lacrimal occurs at about one fourth of the total

328 height of the orbit. The most developed jugal process is the posterior, postorbital, one. This bony

329 extension is very thick anteriorly, but becomes narrower throughout its posterodorsal end, where

330 it contacts the postorbital via an overlapping joint. The postorbital process of the jugal composes

331 most of the posterior edge of the orbit, and the whole anterior border of the lower temporal

332 fenestra.

333 Postorbital. Both postorbitals are preserved; the left one is completely displaced from its original

334 position and the right one shows a slight medial displacement. These bones have a roughly

335 triangular outline and occupy a central position on the temporal region of the skull. The

336 postorbitals make contact dorsally with the frontoparietals, anteriorly with the posterior

337 processes of the jugals and posteriorly with the squamosals. The edges of these bones contribute

338 to the margins of both the upper and lower temporal fenestrae, and also have a small

339 participation in the posterior borders of the orbits.

340 Lacrimal. In AMNH 22555, only the right lacrimal is preserved. This bone is triangular in shape,

341 making contact with the prefrontal and the nasal dorsally and overlying the lacrimal process of

342 the jugal ventrally. The posterior edge of the lacrimal bears a well-developed, lateromedially

343 broad process directed inside the orbit. The lacrimal is pierced by a vast foramen for the exit of

344 the naso-lacrimal duct, which occupies most of the main corpus of this bone. 
345 Squamosal. The squamosal is a curved bone, with its concavity directed anteriorly, where this 346 element comprises most of the posterior border of the lower temporal fenestra. Dorsally, the 347 squamosal contacts the postorbital and frontoparietals. Between these bones there is a smaller 348 concavity that bounds the ventral margin of the upper temporal fenestra. The squamosal ends 349 ventrally with two acute processes. The anterior one sutures with the slim quadratojugal, whereas 350 the posterior one runs parallel to the quadrate and is probably the origin site of the musculus 351 depressor mandibulae. The posterior, convex edge of squamosal makes contact with the 352 opisthotic.

353

354

355

356

357

358

359

360

361

362

363

364

365 366

367

368

369

370

371

372

373

Quadratojugal. This slender bone makes contact with the main corpus of the jugal anteriorly and with one of the ventral processes of the squamosal posteriorly, delimiting ventrally the lower temporal fenestra.

Quadrate. Only the right quadrate is completely preserved. This bone contacts the squamosal, quadratojugal and part of the jugal. The anteroventral end of the quadrate expands to form the helical articular surface with the lower jaw. The quadrate shaft runs medially, parallel to the ventral extension of the squamosal. The inclination of the quadrate with respect to the ventral margin of the maxilla is about 145 degrees.

Supraoccipital. The supraoccipital is a broad plate that forms a large portion of the occiput. Above the dorsal margin of the foramen magnum, this bone develops a low sagittal crest, probably linked to the origin of the musculus rectus capitis. Lateral to the crest, the supraoccipital is pierced by two large pneumatic foramina. The dorsal border of the right posttemporal fenestra is preserved, showing that this opening was inclined downwards (Figure 5).

Opisthotic. In AMNH 22555, both the right and left opisthotics are broken and displaced from their original positions. Although the right element is better preserved, little anatomical information can be drawn from this bone. It can be observed that the opisthotics were configured as wide plates that occupied a considerable portion of the occiput.

Palatine. The structures traditionally regarded, in most pterosaurs, as the palatines were recently reinterpreted as a secondary surface formed by ventral plates of the maxillae (see Ösi et al., 2010; Pinheiro \& Schultz, 2012). The high degree of synostosis, common in Pterodactyloidea, 
374 makes the individualization of palatal elements difficult. In anhanguerids, the palatines probably

375 bordered the suborbital fenestrae medially, the right element being partially preserved in AMNH 37622555 (Figure 4C; Pinheiro \& Schultz, 2012: Figure 4C, D).

377 Pterygoid. Although most of the posterior palatal bones were lost, part of the left pterygoid lies 378 in dorsal view inside the nasoantorbital fenestra. This bone shows a very long and acute rostral 379 process connected to a concave surface, which is followed posteriorly by a transversal ridge. 380 This ridge can be interpreted as part of a vestigial ectopterygoid, already reported for other 381 specimens of Anhanguera (Pinheiro \& Schultz, 2012). In close association, there is a flat, 382 triangular bone of uncertain affinities. It is possible that it represents the posterior extension of 383 the pterygoid, which would contact the basipterygoid caudally.

384 Vomers. The fused vomers form a slim element that partially divides the choanae medially. 385 There is no sign of sutures between the two vomers or between them and other elements of the 386 palate.

\section{7} 388 389 390 391 392 393 394 395 396 397 398 399 400

Dentition. Only the dentition pattern of the upper jaw of AMNH 22555 can be assessed, and it is reminiscent of that seen in other species of Anhanguera. The $1^{\text {st }}$ pair of teeth is located at the tip the rostrum, slightly higher than the $2^{\text {nd }}$ pair, facing anteriorly, as is usual in anhanguerians (Rodrigues \& Kellner, 2013). The alveoli grow in width until the $3^{\text {rd }}$ pair. As is usual in the genus Anhanguera, the $4^{\text {th }}$ and $7^{\text {th }}$ pairs of alveoli are larger than the $5^{\text {th }}$ and $6^{\text {th }}$. From the $8^{\text {th }}$ onwards, the alveoli tend to gradually decrease in width. The distances between the alveoli increase gradually, but are most notably larger from between the $7^{\text {th }}$ and $8^{\text {th }}$ alveoli onwards. As noted above, the maxillary margin is not well preserved and most posteriormost alveoli cannot be assessed, but the dentition would continue until at least the beginning of the nasoantorbital fenestra. Some teeth are preserved, showing a curved and pointed shape and longitudinal ridges where the enamel is present, as typical of anhanguerids (Rodrigues \& Kellner, 2010).

\section{Discussion}

Patterns of premaxillary crest growth in Anhanguera and their taxonomic significance 
401 Morphology of cranial crests has been invariably used as a crucial character in the diagnoses of 402 every single putative species of Anhanguera proposed thus far. Among crest features suggested 403 to distinguish Anhanguera species, the most common is its dorsoventral height and the antero404 posterior extension. The first description of Anhanguera blittersdorffi by Campos \& Kellner 405 (1985) mentioned a "large sagittal crest on the anterior part of the skull, situated on the 406 premaxillas (sic), which ends almost at the beginning of the external naris” (p. 459). Similarly,

407

408

409

410

411

412

413

414

415

416

417

418

419

420

421

422

423

424

425

426

427

428

429

430

Anhanguera spielbergi was described as differing from other species for having a "large

premaxillary sagittal crest, in ratio length-total length skull (sic), which extends dorsally from the anterior aspect until the anterior border of the nasoantorbital fenestra" (Veldmeijer, 2003, p. 43). Also, following the taxonomic revision provided by Kellner and Tomida (2000), the only feature that would distinguish "Anhanguera robustus" from other species of this genus would be a large dentary crest with an anterior margin forming an angle of about $50^{\circ}$ with the dorsal margin of the lower jaw (Kellner and Tomida, 2000, p. 117).

At least one species assigned to Anhanguera would apparently be diagnosed by a small, rather than a large premaxillary crest: according to Kellner and Tomida (2000), Anhanguera piscator would differ in having a long but low premaxillary crest, which does not reach the highest point of the skull (Kellner and Tomida, 2000, p. 7). According to Kellner and Tomida (2000), the two remaining proposed species of the genus, "Anhanguera araripensis" and "Anhanguera santanae", would be distinguished by the antero-posterior extension of the premaxillary crest. In "Anhanguera araripensis", the premaxillary crest would be positioned "right in front of the nasoantorbital fenestra" (p. 105), whereas in "Anhanguera santanae" the premaxillary crest would not reach the anterior margin of the nasoantorbital fenestra, being thus "confined to the anteriormost portion of the skull" (p.109).

Our regression analysis, however, challenges the use of height and anteroposterior extension of the premaxillary crest as robust characters in the diagnosis of anhanguerids at the species level. As demonstrated here, anhanguerid skulls show statistically significant positive allometric growth of the premaxillary crest (see also the work of Bantim et al., 2015). Besides a simple increase in height, the detected pattern of allometric growth also indicates an anteroposterior development of the premaxillary crest following the increase in total skull size (a pattern also corroborated by the analyses of Bantim et al., 2015). 
431 Following the recent discovery of crested pterosaur assemblages preserving a large number of

432 individuals belonging to a single species (Manzig et al., 2014; Wang et al., 2014), it was

433 determined that pterosaur cranial crest development may indeed be strongly controlled by

434 ontogeny and/or sexual dimorphism, as has been suggested previously (for instance, Bennett,

435 1992). The strong positive allometric growth of the premaxillary crests in pterosaurs such as

436 Caiuajara dobruskii (Manzig et al., 2014) and the sexual dimorphism related to the premaxillary

437 crest observed in Hamipterus tianshanensis (Wang et al., 2014) are strong evidence to support

438 the idea that pterosaur premaxillary crests evolved through a mode of sexual selection, as has

439 previously been proposed in several studies (e.g. Hone et al., 2012; Knell et al., 2013). As is

440 characteristic of sexually selective display structures, it is expected that cranial crest size and

441 morphology were strongly intraspecifically variable in pterosaurs. On these grounds, and in

442 agreement with the results presented here, we propose that premaxillary crest characters should

443 be excluded as diagnostic of pterosaur nominal species without more explicit state delimitation

444 boundaries, and at least when the variation does not imply deep changes on the skull

445 architecture, which is not the case for Anhanguera.

446

447

The taxonomy of Anhanguera

448

On the diagnosis of Anhanguera

449

450

451

452

453

454

455

456

457

458

459

460

Kellner (2003) listed synapomorphies of the genus Anhanguera as (1) the presence of an elongate and medially placed nasal process, (2) a foramen on the nasal process, (3) a characteristic size difference in the rostral teeth (in which the $5^{\text {th }}$ and $6^{\text {th }}$ tooth pairs are smaller than the $4^{\text {th }}$ and $7^{\text {th }}$ ones); (4) scapulae length at most $80 \%$ of that of the coracoids, (5) a coracoidal articulation surface with the sternum oval and with a posterior expansion, and (6) a pneumatic foramen on the proximal dorsal surface of the humeri. However, more recently described specimens challenge some of these features and show that they are more widespread among dsungaripteroid pterosaurs. Characters (1) and (2) are present on Ludodactylus sibbicki from the Crato Formation (Frey, Martill \& Buchy, 2003), and characters (4), (5) and (6) are also found in Brasileodactylus sp. (SNSB-BSPG 1991 I 27; Veldmeijer, Meijer \& Signore, 2009) and in Istiodactylus (Hooley, 1913; Andres \& Ji, 2006). Therefore, from these, only character (3) would be unambiguously synapomorphic for Anhanguera. 
461 Naturally, these are characters used in a cladistic sense, but others have also been proposed as 462 diagnostic of the genus. While comparing Anhanguera and Coloborhynchus, Fastnacht (2001) 463 stated that Anhanguera possesses (1) a premaxillary crest beginning more posteriorly instead of 464 at the anterior tip of the rostrum, (2) a premaxillary crest lower than in Coloborhynchus with its 465 height about one third of its length, (3) a thin crest, (4) the anterior end of the rostrum inclined at 466 an angle of about 45 degrees, and (5) the absence of a spoon-shaped distal expansion of the 467 rostrum. From these, our analyses demonstrate that characters (1) and (2) could be attributed to 468 ontogenetic development in the genus Anhanguera. Character (5) is a misinterpretation since the 469 type species, Anhanguera blittersdorffi, has a distal expansion with this morphology (see 470 Rodrigues \& Kellner, 2008). Characters (3) and (4), although useful to distinguish Anhanguera 471 from Coloborhynchus, are also present in Liaoningopterus and Caulkicephalus (Wang \& Zhou, 472 2003; Steel et al., 2005; Rodrigues et al. 2015) and therefore are more widespread within 473 anhanguerids. A very similar set of characters was also discussed by Veldmeijer (2003). This 474 author suggested that AMNH 22555 is a juvenile Coloborhynchus. However, some of the 475 characters used by him to separate Anhanguera and Coloborhynchus, such as the position of the 476 premaxillary crest, are also listed as being possibly explained by ontogenetic variation, a view that is supported by our results. Veldmeijer (2003) also suggested that features present at the posterior part of the skull of AMNH 22555 are more similar to Anhanguera spielbergi (regarded by him as belonging to the genus Coloborhynchus) than to the holotype of "Anhanguera santanae". However, the diagnostic value of these minor differences is dubious. Therefore, it seems that Anhanguera remains diagnosed by a single unambiguous character state, the $5^{\text {th }}$ and 482 $6^{\text {th }}$ tooth pairs being smaller than the $4^{\text {th }}$ and $7^{\text {th }}$ ones, and by combinations of characters.

Here we suggest the following revised diagnosis for Anhanguera, which incorporates the ontogenetic changes discussed above: anhanguerid pterosaurs with premaxillary and dentary median crests; premaxillary crest thin; premaxillary crest largely asymmetric; premaxillary crest begins near but not at the tip of the skull; premaxillary crest not confined to the anteriormost tip of the skull; premaxillary crest grows allometrically in height and length during ontogeny; $5^{\text {th }}$ 488 and $6^{\text {th }}$ upper dental alveoli smaller than the $4^{\text {th }}$ and $7^{\text {th }}$ ones; parietal crest blade-like and thin; palatal ridge modest in depth. 
492

493

494

495

496

497

498

499

500

501

502

503

504

505

506

507

508

509

510

511

512

513

514

515

516

517

518

519

520

When first described by Wellnhofer (1991), AMNH 22555 was referred to "Anhanguera santanae", a pterodactyloid pterosaur described a few years before by the same author and from the same formation (Wellnhofer, 1985). The assignment of AMNH 22555 to "A. santanae" (then regarded as "Araripesaurus"; see Introduction) was made mainly on the basis that both specimens share the same number of bones in the carpal series, besides possessing similar sized skulls, even though the position of their premaxillary crests differed (Wellnhofer, 1991). A close examination of the "A. santanae" holotype (SNSB-BSPG 1982 I 90) and comparison to other skulls now known, however, has revealed to us that AMNH 22555 cannot be confidently referred to this species more than to any other proposed species of Anhanguera.

Although AMNH 22555 is indeed similar to the "Anhanguera santanae" holotype in size and overall skull morphology, the two specimens differ in a series of features (Figure 5). First of all, the frontoparietals of " $A$. santanae" are relatively narrower and project posterodorsally as a thick frontoparietal crest. On the other hand, the frontoparietals of AMNH 22555 are broader and form a much more delicate crest, which is mostly posteriorly extended. The two specimens also differ in the morphology of the jugal: the lacrimal process of this bone is much broader in $A$. santanae than in AMNH 22555.

Differences between AMNH 22555 and "A. santanae" also extend to the occipital and palatal regions. In occipital view, it is notable that the supraoccipital crest is much more conspicuous in “A. santanae” than in AMNH 22555. Also, although the occiput of AMNH 22555 is not well preserved, the dorsal margin of the posttemporal fenestra is well marked and reveals that this opening was probably directed downwards, unlike the condition observed in the "A. santanae" holotype. As a consequence of the poor preservation, however, this characteristic must be regarded with caution. In palatal view, it is remarkable that in AMNH 22555 the fusion of the palatal plates of the maxillae develops into a strong palatal ridge (although not as deep as observed in Tropeognathus) that is followed posteriorly by a slight convexity of the palatal occlusal surface. "A. santanae" also bears a palatal ridge, but this structure is much less pronounced and extends posteriorly to a region closer to the choanae than that seen in AMNH 22555. In addition, the choanal morphology is also different between the specimens, with those of AMNH 22555 being distinctly rounder and more lateromedially expanded. 
521 In spite of these remarkable differences between AMNH 22555 and the "Anhanguera santanae"

522 holotype (SNSB-BSPG 1982 I 90), none of the characters listed above have had their

523 distributions well mapped for Anhanguera, and may fall within the range of intraspecific

524 variation for this genus. In addition, it is noteworthy that allegedly diagnostic features of

525 Anhanguera nominal species are, in most cases, subtle and poorly defined, especially those

526 which are related to the presence and morphology of the premaxillary crest. As discussed, the

527 premaxillary crest shows significant allometric growth within Anhanguera-like pterodactyloids,

528 demonstrating that this structure is at least partially body size-dependent and therefore has

529 limited use for taxonomic purposes. Bearing this in mind, we reassess here the significance of

530 anatomical features of the premaxillary crest traditionally thought to support Anhanguera

531 species, and elucidate the impact of this on the taxonomy of this genus.

On the validity of "Anhanguera santanae" and other species of Anhanguera

534 A reappraisal of the purportedly diagnostic features of the individual Anhanguera species

535 revealed that most, if not all, of the characters that are currently used to define the separate

536 species are probably well inside the range of intraspecific variation. Considering this, it is

537 pertinent to inquire about the validity of each one of the species attributed to this genus.

538 When first described, "Anhanguera santanae" was differentiated from other pterosaurs on the

539 basis of characters that are today known to be widely distributed among other Santana Group

540 ornithocheiroids. A complete discussion of the validity of the diagnostic features originally

541 proposed for “A. santanae” was made by Kellner \& Tomida (2000). As a conclusion, these

542 authors stated that the only remaining diagnostic character for this taxon would be the position of

543 the premaxillary crest, well anterior to the nasoantorbital fenestrae. It is noteworthy that the

544 premaxillary crest itself is not preserved on "A. santanae" holotype, and its presence is inferred

545 by the acute dorsal margin of the premaxillae close to the anterior extremity of the specimen, as

546 preserved. One of the specimens analyzed in the present allometric regression, SMNK PAL

547 1136, presents a premaxillary crest that can be presumed to be positioned as far from the

548 nasoantorbital opening as inferred in the holotype of "A. santanae". As discussed, premaxillary

549 crest characters are here regarded as unfit for the diagnosis of nominal anhanguerid species, what 
550 means that "A. santanae" holotype lacks unambiguous diagnostic features and should be

551 considered as a nomen dubium.

552 Anhanguera blittersdorffi, the type species of Anhanguera, was first diagnosed by characters that

553 later proved to be diagnostic of more inclusive clades, such as the presence and morphology of

554 the premaxillary and frontoparietal crests and the presence of a distal expansion and of larger

555 teeth at the tip of the rostrum (Campos \& Kellner, 1985). Actually, A. blittersdorffi has the

556 standard morphology of Anhanguera and, after the description of other anhanguerids, it became

557 difficult to recognize unique characters for this species. A subsequent revision (Kellner \&

558 Tomida, 2000) proposed diagnostic characters of the species as a "lower skull with a

559 proportionally shorter quadrate". Those characters, however, are subjective and ambiguous, and

560 lack a quantified definition to delimit the state boundaries. Besides the holotype, only one

561 additional specimen has been formally attributed to A. blittersdorffi (Pz-DBAV-UERJ 40)

562 (Kellner and Tomida, 2000), though the latter still lacks an anatomical description. Remarkably,

563 the number of alveoli on A. blittersdorffi upper jaws (52) is higher than in any other proposed

564 Anhanguera species and this might be a more suitable diagnostic character for this taxon.

565 "Anhanguera araripensis" was described based on a very incomplete skull with associated

566 postcranial bones by Wellnhofer (1985). As was the case for A. blittersdorfii, "A. araripensis"

567 was first diagnosed by characters that later were demonstrated to be more widespread among

568 anhanguerids or dependent on ontogenic status of specimens. After the revision of Kellner \&

569 Tomida (2000), only two characters remained as diagnostic for this species: the dorsal margin of

570 the premaxillae being "keel shaped" up to the anterior end of the nasoantorbital fenestrae (a

571 character described as being related to the position of the premaxillary crest, which is not

572 preserved at the holotype), and the presence of small lateral projections on the basioccipital

573 processes of the pterygoids (Kellner, 1991) (Figure 6, D). Based on this character, other

574 specimens have also been referred to this species, such as MN 4735-V (Kellner \& Tomida, 2000)

575 and SAO 16494 (Veldmeijer, 2003; Veldmeijer, 2006). We agree that the "keel shaped" dorsal

576 margin of the premaxillae is probably related to the presence and morphology of the

577 premaxillary crest and, for the reasons described above, challenge the taxonomic value of this

578 character. Regarding the lateral projections of the pterygoids inside the subtemporal fenestrae,

579 we consider this character as problematic, because it is probably related to the bone growth 
580 between different elements of the adductor musculature that crossed the subtemporal openings.

581 Also, these projections are exceptionally delicate and were probably abraded on not so well 582 preserved skulls. Remarkably, specimens such as the holotype of Tropeognathus mesembrinus

583 (SNSB-BSPG 1987 I 46) and A. blittersdorffi (MN 4805-V) have very discrete bulges at this 584 same location (Figure 6, E). Thus, we here regard the holotype of “A. araripensis" as 585 nondiagnostic and, for this reason, "Anhanguera araripensis" should also be considered as a 586 nomen dubium.

587 “Anhanguera robustus", was originally referred to the genus Tropeognathus by Wellnhofer 588 (1987) and later assigned to Anhanguera (Kellner \& Campos, 1988). This taxon was originally 589 diagnosed by the presence of a well-developed dentary crest, with a straight anterior margin; and 590 by a spoon-like anterior expansion of the dentaries and long anterior teeth. As has already been 591 observed by Kellner \& Tomida (2000), strong anterior teeth associated to a lateral expansion of 592 the dentaries are considered to be widespread among anhanguerids. The other supposedly 593 diagnostic characters are related to the dentary sagittal crest and are probably associated to the 594 apparently advanced ontogenetic stage of the specimen (SNSB-BSPG 1987 I 47). Thus, we also 595 consider "Anhanguera robustus" as a nomen dubium.

596 Despite its large body size, the holotype of Anhanguera piscator presents clear evidence of an 597 early ontogenetic stage, which partially explains the presence of the low premaxillary crest that 598 was regarded by Kellner and Tomida (2000) as diagnostic for this species. Our analysis 599 demonstrates that premaxillary crest height in this species cannot be explained by allometric 600 growth alone, but nonetheless we consider this character alone to be inappropriate for the 601 diagnosis of anhanguerids. Kellner and Tomida (2000) indicated another cranial character as 602 diagnostic for this taxon: a "basisphenoid constricted in the middle part" (Kellner \& Tomida, 603 2000, p. 7). This feature cannot be accessed in SNSB-BSPG 1982 I 89 (“Anhanguera 604 araripensis”) or SNSB-BSPG 1987 I 47 (“Anhanguera robustus”). Although this character still 605 lacks an unambiguous morphometric definition, basisphenoid morphology in A. piscator 606 holotype is indeed different from what is observed in Anhanguera blittersdorffi and SNSB-BSPG 6071982 I 90 (“Anhanguera santanae"), resembling the condition of Anhanguera spielbergi. Other 608 proposed diagnostic features of $A$. piscator are associated to the postcranial skeleton, which is 609 poorly preserved or absent in most other Anhanguera holotypes. A. piscator is here retained as a 
610 valid taxon, at least until more information about the distribution of these postcranial characters

611 and the basisphenoid morphology becomes clearer within Anhangueridae.

612 Veldmeijer (2003) considered Anhanguera spielbergi to be a representative of Coloborhynchus, 613 including in the diagnosis of this species an "ill-defined, almost absent (...) palatinal ridge and 614 corresponding mandibular groove; mandibular groove not extending onto spoon-shaped 615 expansion; slight, almost absent, ventrolaterally extending tooth-bearing maxillae; large 616 premaxillary sagittal crest, in ratio length-total length skull, which extends dorsally from the 617 anterior aspect until the anterior border of the nasoantorbital fenestra; strongly medial bended 618 rami; sternum with rounded triangular posterior plate of which the length is as long as the width" 619 (Veldmeijer, 2000, p. 43). Although the palatal ridge of $A$. spielbergi is indeed weaker than that 620 which is observed in other Anhanguera holotypes, it is still not clear how this character is 621 affected by ontogeny, the same also being a potential issue for the mandibular groove 622 morphology. As we have discussed, premaxillary crest morphology is here regarded as 623 inappropriate for species-level diagnoses. Furthermore, a medial bending of mandibular rami 624 cannot be assessed in most of the other holotypes, but is present in other complete anhanguerid 625 mandibles (for instance, "Anhanguera robustus"). Although the intrageneric variation of the 626 remaining characters is still unclear, we regard $A$. spielbergi as a valid taxon, a taxonomic 627 statement that requires further testing through more comprehensive sampling within the genus.

628

A highly diverse genus or an exceptionally biased record?

630

631

632

633

634

635

636

637

638

639

Specimens attributable to Anhanguera often present slight differences on their skull anatomies, especially with respect to the size and morphology of the premaxillary crest. Historically, these different morphotypes were used to base the definition of new taxa, which at the time was not necessarily incorrect, given the fact that our knowledge about ontogenetic and sexual variability connected to crest morphology was (and still is) incipient. Nowadays, however, this practice has resulted in an abundance of nominal species with, as we demonstrate, continuous morphologies. As a result, it is considerably difficult to attribute any new material to a previously described species with any proper degree of certainty. This same issue was detected before in other fossil localities that have, historically, yielded pterosaur fossils, such as the Niobrara and Pierre Shale formations of the USA (Pteranodon and Nyctosaurus sites) and the Solnhofen limestones of 
640 Bavaria, Germany. Similarly to what we discuss here for Anhanguera, the diversity of taxa found

641 in those sites has been reassessed taking into account the influence that ontogeny, sexual

642 dimorphism, individual differences and time may have on morphological disparities that have

643 previously been considered to be of taxonomic significance (e.g. Bennett, 1992; Bennett, 1994;

644 Bennett, 1995).

645 A possible overestimation in the anhanguerid diversity of the Romualdo Formation was also 646 already pointed out by Kellner and Tomida (2000). These authors commented on the lack of 647 comparable elements between some of the taxa and on potential intraspecific variations for the 648 taxonomic inflation, although not making reference to other potential biases.

649 As the relation between morphological disparity and speciation is vague, the application of the 650 prevailing definition of the biological species concept (grounded on reproductive isolation) to the 651 fossil record is exceedingly challenging (e.g. Gingerich, 1985; Bennett, 1994; Kellner, 2010).

652 This is even more delicate when one is dealing with lineages that lack extant analogues or direct 653 descendants, as is the case for pterosaurs. In order to distinguish fossil and extant species, the 654 amount of morphological variation among studied specimens is less important than the presence 655 of morphological discontinuities (Gingerich, 1985). Disparate morphologies that show 656 continuous intermediates in the sample are, thus, better explained by intraspecific variation or 657 temporal evolutionary effects (this later only recognizable in the fossil record).

658 As we demonstrated, most of the allegedly diagnostic characters traditionally used to distinguish 659 proposed Anhanguera species display continuous variation in the available sample pool and are 660 correlated to skull size, and as a result are generally unfit for taxonomic purposes. The detected 661 residual variation (not attributable to the allometric growth of the skull) is, in most of the cases, 662 characterized by disparate conditions linked by intermediate morphologies. However, in some 663 other cases, as the premaxillary crest morphology of specimen MN 4735-V and Anhanguera 664 piscator holotype illustrates, the residual variation is well beyond the condition expected for 665 animals of their sizes, and therefore perhaps more reflective of taxonomic discrepancies. We 666 discuss, here, possible explanations for this peculiar pattern of morphological disparity of 667 Anhanguera-like pterosaurs.

668 A natural ecological question that follows the assumption that Romualdo Formation pterosaur 669 taxa were sympatric and coeval, is how such a large number of taxa with supposedly overlapping 
670 ecological niches may have coexisted. However, competitive exclusion of species happens only 671 when the resources are scarce to the point of limiting population growth. If we assume, as is 672 likely, that Anhanguera species competed for prey, sufficiently high fish populations could 673 sustain several sympatric piscivorous species. This, however, would result in an apparently 674 aberrant community structure, and the pattern observed in the fossil record may be better 675 explained by the influence of biological and stratigraphic bias.

676 Although our allometric regressions are not per se direct evidence that premaxillary crests grew 677 with age, the strong correlation of crest development with respect to skull size makes it very 678 likely that the patterns observed here indeed reflect an ontogenic growth trajectory. Allometric 679 growth of skull ornaments in pterosaurs was recently confirmed by the discovery of 680 monospecific bonebeds with fairly complete growth series (e.g. Manzig et al., 2014). The strong 681 positive allometry demonstrated here (as in pterosaurs like Caiuajara dobruskii) is characteristic 682 of sexually selected traits (Tomkins et al., 2010), which are exceptionally variable within 683 species. Thus, it is likely that a considerable amount of the morphological disparity observed in 684 anhanguerids is attributable to intraspecific variation. Sexually selected characters tend also to be 685 sexually dimorphic, and sexual dimorphism related to cranial premaxillary crests was present in 686 pterosaurs (e.g. Wang et al., 2014). It is possible that anhanguerid premaxillary crests were also 687 sexually dimorphic, which would explain at least some of the residual variation recovered by our 688 analyses. However, small sample size and the probable effect of stratigraphic biases (as we 689 discuss below) makes it impossible to assess this hypothesis at the time. It is consensual that 690 robust synecological inferences based on Romualdo Formation fossils are impossible based on 691 museum specimens alone. The reason for this hindrance is that the commercial exploitation of 692 Romualdo Formation fossil bearing strata unfortunately disregards important field data, such as 693 those concerning the stratigraphic distribution and abundance of species. Virtually all the 694 Romualdo Formation specimens deposited in museums and universities throughout the world (i. 695 e., those available for scientific research) fall under this scenario. The high commercial value of 696 complete specimens or specific taxa, such as pterosaurs, created a strong collection bias and, as a 697 result, museum specimens are not representative of the actual Romualdo Formation diversity 698 (Fara et al., 2005; Vila Nova et al., 2011). Stratigraphically controlled excavations on Romualdo 699 Formation are still incipient (Fara et al., 2005; Vila Nova et al., 2001). The few works dealing 700 with the results of these enterprises, however, have already demonstrated the presence of strong 
701 geographic and stratigraphic biases, which may impact upon our understanding of Romualdo

702 Formation pterosaur taxonomy and diversity.

703 The yet incipient results derived from controlled excavations on the Romualdo Formation

704 already demonstrate clear evidence for faunal turnover, through the substitution of a basal fish

705 assemblage dominated by the gonorynchiform Tharrhias by upper strata where the most

706 abundant taxon is the aspidorhynchid Vinctifer (Fara et al., 2005). Possible reasons for this

707 faunal interchange have still not been investigated. However, considering the presumably low

708 deposition rate of the shales that embed Romualdo Formation fossil concretions, it is likely that a

709 substantial time interval was associated with this turnover.

710 The temporal resolution of Romualdo Formation fossils was never estimated and several events

711 of mass mortality probably took place (Fara et al., 2005; Vila Nova et al., 2001). Thus, based on

712 the present state of knowledge, it is likely that at least some of the Romualdo Formation

713 pterosaurs were not coeval. This could also be an explanation for the apparently high number of

714 similar species of anhanguerians in the same geological unit, since we might have a sample that

715 includes species separated in time. Thus, it is possible that different Anhanguera-like

716 morphotypes may represent subtle morphological changes in a lineage undergoing anagenetic

717 evolution. A similar pattern was proposed by Bennet (1994) for different Pteranodon species

718 (but see Kellner, 2010). Stratigraphically controlled excavations, such as the ones reported by

719 Fara et al. (2005) and Vila Nova et al. (2001) hopefully will shed light on this issue.

720

721

\section{Conclusions}

722 Even though more than a dozen relatively complete skulls referable to the Anhangueridae and

723 closely related taxa are nowadays held in public collections, this is the first study to perform a

724 comprehensive morphometric analysis of continuous morphological features seen in the skulls of

725 members of this clade. As a result, characters related to both dorsoventral height and the

726 anteroposterior extension of the premaxillary crest are found to be allometrically correlated to

727 skull size, and therefore at least in part to ontogeny. The observation that anhanguerid

728 premaxillary crest morphology is size-dependent makes also means that it is largely unfit to be

729 used as a diagnostic character for delimiting species, as has been commonly proposed for this 
730 group in the past. A taxonomic review excluding these characters reveals that as few as three

731 Anhanguera species are potentially definitively valid: A. blittersdorffi, A. piscator and A.

732 spielbergi. The significance of the minor, continuous differences between specimens is still not

733 entirely clear, though. Controlled stratigraphic studies on the Romualdo Formation demonstrate

734 evidence of faunal turnover in fishes, and the same could be true also for pterosaurs. Thus, the

735 seemly continuous morphological changes observed in anhanguerids could possibly be explained

736 by anagenetic evolution. However, as virtually all pterosaur specimens from this unit lack

737 fundamental stratigraphic information, it is impossible to test this hypothesis at the present.

738

739 Acknowledgments

740 For granting access to AMNH 22555 and other pterosaur specimens, the authors are particularly

741 indebted to Mark Norell and Carl Mehling (AMNH). Also, we would like to thank the following

742 people for allowing the study of specimens under their care and for kind help during visits:

743 Álamo Saraiva and João Kerensky (MPSC); Oliver Rauhut and Markus Moser (SNSB-BSPG);

744 Alexander Kellner and Helder Silva (MN); Eberhard Frey (SMNK); Rainer Schoch (SMNS);

745 Sandra Chapman and Lorna Steel (NHMUK); Dan Pemberton and Matt Riley (CAMSM);

746 Stephen Hutt (IWCMS); David Gelsthorpe (MANCH); Urs Oberli (SAO); Jon de Vos

747 (Naturalis); Mauro Bon (MSN); and Wang Xiaolin (IVPP). FLP thanks Cesar Schultz for

748 advisement on pterosaurs, TR thanks Alexander Kellner for advisement and support. We also

749 acknowledge Pedro Godoy (University of Birmingham) for comments and suggestions on the

750 methodology applied here, Jonathan Tennant for suggestions and review of the language, as well

751 as Renan Bantim and an anonymous referee for valuable comments on an early version of this

752 paper.

753

754 References

755 Andres B, Ji Q. 2006. A new species of Istiodactylus (Pterosauria, Pterodactyloidea) from the

756 Lower Cretaceous of Liaoning, China. Journal of Vertebrate Paleontology 26: 70-78. DOI:

757 http://dx.doi.org/10.1671/0272-4634(2006)26[70:ANSOIP]2.0.CO;2. 
758 Assine ML. 2007. Bacia do Araripe. Boletim de Geociências da Petrobrás 15: 371-389.

759 Bantim RAM, Saraiva AAF, Oliveira GR, Sayão JM. 2014. A new toothed pterosaur

760 (Pterodactyloidea: Anhangueridae) from the Early Cretaceous Romualdo Formation, NE Brazil.

761 Zootaxa 3869:201-223. DOI: http://dx.doi.org/10.11646/zootaxa.3869.3.1.

762 Bantim RAM, Saraiva AAF, Sayão JM. 2015. Skull variation and the shape of the sagittal

763 premaxillary crest in anhanguerid pterosaurs (Pterosauria, Pterodactyloidea) from the Araripe

764 Basin, Northeast Brazil. Historical Biology 27: 656-664. DOI:

765 http://dx.doi.org/10.1080/08912963.2014.921818.

766 Bennett SC. 1992. Sexual dimorphism of Pteranodon and other pterosaurs, with comments on 767 cranial crests. Journal of Vertebrate Paleontology 12: 422-434.

768 Bennett SC. 1993. The ontogeny of Pteranodon and other pterosaurs. Paleobiology 19: 92-106.

769 Bennett SC. 1994. Taxonomy and systematics of the Late Cretaceous pterosaur Pteranodon

770 (Pterosauria, Pterodactyloidea). Occasional Papers of the Natural History Museum, The

771 University of Kansas, Lawrence, Kansas 169:1-70.

772 Bennett SC. 1995. A statistical study of Rhamphorhynchus from the Solnhofen limestone of 773 Germany: year-classes of a single large species. Journal of Paleontology 69: 569-580. DOI: 774 https://doi.org/10.1017/S0022336000034946.

775 Campos DA, Kellner AWA. 1985. Panorama of the flying reptiles study in Brazil and South 776 America. Anais da Academia Brasileira de Ciências 57: 453-466.

777 Campos HBN, Headden JA, Frey E. 2013. New material of the enigmatic ornithocheiroid

778 Cearadactylus atrox from the Santana Formation (Lower Cretaceous), northwestern Brazil. Short 779 communications, International Symposium on Pterosaurs. p. 36-39.

780 Drake AG, Klingenberg CP. 2008. The pace of morphological change: Historical transformation 781 of skull shape in St Bernard dogs. Proceedings of the Royal Society B, Biological Sciences 275: 782 71-76. DOI: 10.1098/rspb.2007.1169.

783 Fara E, Saraiva AAF, Campos DA, Moreira JKR, Siebra DC, Kellner AWA. 2005. Controlled 784 excavations in the Romualdo Member of the Santana Formation (Early Cretaceous, Araripe 
785 Basin, northeastern Brazil): stratigraphic, palaeoenvironmental and palaeoecological 786 implications. Paleogeography, Paleoclimatology, Paleoecology 218: 145-160. DOI:

787 http://dx.doi.org/10.1016/j.palaeo.2004.12.012.

788 Fastnacht M. 2001. First record of Coloborhynchus (Pterosauria) from the Santana Formation 789 (Lower Cretaceous) of the Chapada do Araripe, Brazil. Paläontologische Zeitschrift 75: 23-36. 790 DOI: 10.1007/BF03022595.

791 Frey E, Martil DM. 1994. A new pterosaur from the Crato Formation (Lower Cretaceous, 792 Aptian) of Brazil. Neues Jahrbuch für Geologie und Paläontologie, Abhandlungen 194:379-412.

793 Frey E, Martill DM, Buchy M-C. 2003. A new crested ornithocheirid from the Lower Cretaceous 794 of northeastern Brazil and the unusual death of an unusual pterosaur. In: Buffetaut E, Mazin J-; 795 M, eds. Evolution and paleobiology of pterosaurs. London: Geological Society. pp 55-63. DOI: 796 10.1144/GSL.SP.2003.217.01.05.

797 Gingerich PD. 1985. Species in the fossil record: concepts, trends, and transitions. Paleobiology 798 11: 27-41. DOI: https://doi.org/10.1017/S0094837300011374.

799 Hone DWE, Naish D, Cuthill IC. 2012. Does mutual sexual selection explain the evolution of 800 head crests in pterosaurs and dinosaurs? Lethaia 45: 139-156. DOI: 10.1111/j.1502801 3931.2011.00300.x.

802 Hooley RW. 1913. On the skeleton of Ornithodesmus latidens; an ornithosaur from the Wealden 803 Shales of Atherfield (Isle of Wight). Quarterly Journal of the Geological Society 96: 372-422. 804 DOI: 10.1144/GSL.JGS.1913.069.01-04.23.

805 Kaup JJ. 1834. Versuch einer Einteilung der Saugethiere in 6 Stämme und der Amphibien in 6 806 Ordnungen. Isis 3: 311-315.

807 Kellner AWA. 1990. Os répteis voadores do Cretáceo brasileiro. Anuário do Instituto de 808 Geociências 12: 86-106.

809 Kellner AWA. 1991. Pterossauros do Brasil. Unpublished M. Sc. thesis. 543 p. 
810 Kellner AWA. 2003. Pterosaur phylogeny and comments on the evolutionary history of the 811 group. In: Buffetaut E, Mazin J-;M, eds. Evolution and paleobiology of pterosaurs. London: 812 Geological Society. pp 105-137. DOI: 10.1144/GSL.SP.2003.217.01.10.

813 Kellner AWA. 2010. Comments on the Pteranodontidae (Pterosauria, Pterodactyloidea) with the 814 description of two new species. Anais da Academia Brasileira de Ciências 82:1063-1084.

815 Kellner AWA, Campos DA. 1988. Sobre um novo pterossauro com crista sagital da Bacia do 816 Araripe, Cretáceo Inferior do nordeste do Brasil. Anais da Academia Brasileira de Ciências $817 \quad 60: 459-469$.

818 Kellner AWA, Campos DA, Sayão JM, Saraiva AAF, Rodrigues T, Oliveira G, Cruz LA, Costa 819 FR, Silva HP, Ferreira JS. 2013. The largest flying reptile from Gondwana: a new specimen of 820 Tropeognathus cf. T. mesembrinus Wellnhofer, 1987 (Pterodactyloidea, Anhangueridae) and 821 other large pterosaurs from the Romualdo Formation, Lower Cretaceous, Brazil. Anais da 822 Academia Brasileira de Ciências 85:113-135. DOI: http://dx.doi.org/10.1590/S0001$823 \quad 37652013000100009$.

824 Kellner AWA, Tomida Y. 2000. Description of a new species of Anhangueridae 825 (Pterodactyloidea) with comments on the pterosaur fauna from the Santana Formation (Aptian826 Albian), northeastern Brazil. National Science Museum Monographs 17: 1-135.

827 Klingenberg CP. 2011. MorphoJ: an integrated software package for geometric morphometrics. 828 Molecular Ecology Resources 11:353-357. DOI: 10.1111/j.1755-0998.2010.02924.x.

829 Knell RJ, Naish D, Tomkins JL, Hone DWE. 2013. Sexual selection in prehistoric animals: 830 detection and implications. Trends in Ecology \& Evolution 28:38-47. DOI:

831 http://dx.doi.org/10.1016/j.tree.2012.07.015

832 Manzig PC, Kellner AWA, Weinschütz LC, Fragoso CE, Vega CS, Guimarães GB, Godoy LC, 833 Liccardo A, Ricetti JHZ, Moura CC. 2014. Discovery of a rare pterosaur bone bed in a 834 Cretaceous desert with insights on ontogeny and behavior of flying reptiles. PLoS ONE 9(8): 835 e100005. DOI: http://dx.doi.org/10.1371/journal.pone.0100005.

836 Ösi A, Prondvai E, Frey E, Pohl B. 2010. New interpretation of the palate of pterosaurs. The 837 Anatomical Record 293: 243-258. DOI: 10.1002/ar.21053. 
838 Pinheiro FL, Schultz CL. 2012. An unusual pterosaur specimen (Pterodactyloidea,

839 ?Azhdarchoidea) from the Early Cretaceous Romualdo Formation of Brazil, and the evolution of 840 the pterodactyloid palate. PLOS ONE 7(11): e50088. DOI:10.1371/journal.pone.0050088.

841 Plieninger F (1901.) Beiträge zur Kenntnis der Flugsaurier. Palaeontographica 48: 65-90.

842 Price LI. 1971. A presença de Pterosauria no Cretáceo Inferior da Chapada do Araripe, Brasil. 843 Anais da Academia Brasileira de Ciências 43: 451-461.

844 Rodrigues T, Jiang S, Cheng X, Wang X, Kellner AWA.(2015. A new toothed pteranodontoid 845 (Pterosauria, Pterodactyloidea) from the Jiufotang Formation (Lower Cretaceous, Aptian) of 846 China and comments on Liaoningopterus gui Wang and Zhou, 2003. Historical Biology 27:782847 795. DOI: 10.1080/08912963.2015.1033417.

848 Rodrigues T, Kellner AWA. 2008. Review of the pterodactyloid pterosaur Coloborhynchus. 849 Zitteliana B 28: 219-228.

850 Rodrigues T, Kellner AWA. 2010. Note on the pterosaur material described by Woodward from 851 the Recôncavo Basin, Lower Cretaceous, Brazil. Revista Brasileira de Paleontologia 13: 159852 164. DOI: $10.4072 /$ rbp.2010.2.08.

853 Rodrigues T, Kellner AWA. 2013. Taxonomic review of the Ornithocheirus complex 854 (Pterosauria) from the Cretaceous of England. Zookeys 308: 1-112. DOI: 855 https://doi.org/10.3897/zookeys.308.5559.

856 Rohlf FJ. 2010. TpsDig, version 2.16, Department of Ecology and Evolution, State University of 857 New York at Stony Brook. Available at http://life.bio.sunysb.edu/morph/

858 Saraiva AAF, Hessel MH, Guerra NC, Fara E. 2007. Concreções calcárias da Formação Santana, 859 Bacia do Araripe: Uma proposta de classificação. Estudos Geológicos 17: 40-57.

860 Steel L, Martill DM, Unwin DM, Winch JD. 2005. A new pterodactyloid pterosaur from the 861 Wessex Formation (Lower Cretaceous) of the Isle of Wight, England. Cretaceous Research 26: 862 686-698. DOI: http://dx.doi.org/10.1016/j.cretres.2005.03.005.

863 Tomkins JL, LeBas NR, Witton MP, Martill DM, Humphries S. 2010. Positive allometry and the 864 prehistory of sexual selection. The American Naturalist 176:141-148. DOI: 10.1086/653001 
865 Unwin DM. 2001. An overview of the pterosaur assemblage from the Cambridge Greensand 866 (Cretaceous) of Eastern England. Mitteilungen aus dem Museum für Naturkunde in Berlin, 867 Geowissenschaftliche Reihe 4: 189-221. DOI 10.1002/mmng.20000030109.

868 Veldmeijer AJ. 2003. Description of Coloborhynchus spielbergi sp. nov. (Pterodactyloidea) from 869 the Albian (Lower Cretaceous) of Brazil. Scripta Geologica 125: 35-139.

870 Veldmeijer AJ. 2006. Toothed pterosaurs from the Santana Formation (Cretaceous; Aptian871 Albian) of northeastern Brazil. A reappraisal on the basis of newly described material.

872 Unpublished doctoral thesis. 269 p.

873 Veldmeijer AJ, Meijer HJM, Signore M. 2006. Coloborhynchus from the Lower Cretaceous 874 Santana Formation, Brazil (Pterosauria, Pterodactyloidea, Anhangueridae); an update. PalArch's 875 Journal of Vertebrate Palaeontology 3:15-29

876 Veldmeijer AJ, Meijer HJM, Signore M. 2009. Description of pterosaurian (Pterodactyloidea: 877 Anhangueridae, Brasileodactylus) remains from the Lower Cretaceous of Brazil. Deinsea 13: 987840.

879 Vila Nova BC, Saraiva AAF, Moreira JKR, Sayão JM. 2011. Controlled excavations in the 880 Romualdo Formation Lagerstätte (Araripe Basin, Brazil) and pterosaur diversity: remarks based 881 on new findings. Palaios 26: 173-179. DOI: http://dx.doi.org/10.2110/palo.2010.p10-072r.

882 Wang X, Kellner AWA, Jiang S, Wang Q, Ma Y, Paidoula Y, Cheng X, Rodrigues T, Meng X, 883 Zhang J, Li N, Zhou Z. 2014. Sexually dimorphic tridimensionally preserved pterosaurs and their 884 eggs from China. Current Biology 24:1323-1330. DOI:

885 http://dx.doi.org/10.1016/j.cub.2014.04.054.

886 Wang X, Zhou Z. 2003. Two new pterodactyloid pterosaurs from the Early Cretaceous Jiufotang 887 Formation of Western Liaoning, China. Vertebrata Palasiatica 41: 34-41.

888 Wellnhofer P. 1985. Neue Pterosaurier aus der Santana-Formation (Apt) der Chapada do 889 Araripe, Brasilien. Palaeontographica Abt. A 187: 105-182.

890 Wellnhofer P. 1987. New Crested Pterosaurs from the Lower Cretaceous of Brazil. Mitteilungen 891 der Bayerischen Staatssammlung für Paläontologie und historische Geologie 27: 175-186. 
892 Wellnhofer P. 1991. Weitere Pterosaurierfunde aus der Santana-Formation (Apt) der Chapada do

893 Araripe, Brasilien. Palaeontographica Abt. A 215: 43-101.

894 Witton, MP. 2013. Pterosaurs: natural history, evolution, anatomy. Princeton: Princeton

895 University Press.

896

897 Legends to the figures

898 Figure 1. Location map of the Araripe Basin, northeastern Brazil and simplified stratigraphic 899 chart of the Santana Group. Levels where pterosaur fossils are found are indicated. Modified 900 from Pinheiro \& Schultz (2012).

901

902 Figure 2. Specimen AMNH 22555, a partial anhanguerid skeleton. Some selected elements are 903 figured in detail. A, pelvic region in dorsal view; B, torso in dorsal view; C, D, E, sixth cervical 904 vertebrae in, respectively, anterior, dorsal and right lateral views; F, G, right mandibular ramus 905 in, respectively, medial and lateral views; H, left scapula in dorsal view; I, left coracoid in lateral 906 view; J, distal carpals in distal view; K, proximal carpals in distal view. Scale bars equal to 50 $907 \mathrm{~mm}$. Line drawings of some bones were modified from Witton (2013).

908 Figure 3. Geometric morphometric analysis of twelve skulls referable to Anhanguera (red dots) 909 and closely related taxa (blue dots) of the regression score on centroid size log. Used landmarks 910 are plotted in the skull of Anhanguera blittersdorffi holotype. Deformation grids and wireframe 911 graphs display morphological components predicted by allometry in Barbosania (red) and

912 Tropeognathus cf. mesembrinus (blue).

913 Figure 4. Interpretative drawings of AMNH 22555 skull in A, right lateral, B, dorsal and C,

914 palatal views. Abbreviations: ch, choanae; ec, ectopterygoid; fp, frontoparietal; j, jugal; 1, 915 lacrimal; m, maxilla; n, nasal; naof, nasoantorbital fenestra; op, opisthotic; pf, prefrontal; pl, 916 palatine; po, postorbital; pm, premaxilla; pt, pterygoid; q, quadrate; so, supraorbital; sq, 917 squamosal; v, vomers. Scale bar equals $100 \mathrm{~mm}$.

918 Figure 5. Comparison between the skulls of AMNH 22555 and Anhanguera santanae holotype 919 (SNSB-BSPG 1982 I 90). A, AMNH 22555 skull in lateral view; B, Interpretative drawing of the 
920 photo in A. C, Anhanguera santanae (SNSB-BSPG 1982 I 90) skull in lateral view (mirrored);

921 E, F, G, H, palatal views and interpretative drawings of, respectively, AMNH 22555 and $A$.

922 santanae (SNSB-BSPG 1982 I 90) skulls; I, J, interpretative drawings of the occipital views of,

923 respectively, AMNH 22555 and A. santanae (SNSB-BSPG 1982 I 90) skulls. Scale bar equal to

$924100 \mathrm{~mm}$ in A, B, C, D, E, F, G, H, and $50 \mathrm{~mm}$ in I, J. Abbreviations: ch, choanae; fpc,

925 frontoparietal crest; 1pj, lacrimal process of jugal; pr, palatal ridge; ptf, posttemporal fenestra;

926 soc, supraoccipital crest.

927 Figure 6. Overview of the holotypes of several Anhanguera species. A, Anhanguera blittersdorffi

928 (MN 4805-V) in lateral view. B, C, F, “Anhanguera araripensis" (SNSB-BSPG 1982 I 89) in

929 dorsal, ventral, and lateral views, respectively. D, detail of C; arrow points a lateral projection of

930 the pterygoid. E, detail of the Tropeognathus mesembrinus (SNSB-BSPG 1987 I 46); arrow

931 points a bulge laterally on the pterygoid. G, H, holotype of "Anhanguera robustus"( SNSB-

932 BSPG 1987 I 47) in dorsal and lateral views, respectively. I, holotype of Anhanguera spielbergi

933 (RGM 401880$)$ in lateral view. 


\section{Table 1 (on next page)}

Anhanguera taxonomy

Synopsis of the named species of Anhanguera from the Romualdo Formation 
Table I. Synopsis of the named species of Anhanguera from the Romualdo Formation.

\begin{tabular}{|c|c|c|c|}
\hline Species & $\begin{array}{l}\text { Taxonomic status in } \\
\text { the present work }\end{array}$ & Known specimens & Diagnosis \\
\hline $\begin{array}{l}\text { Anhanguera blittersdorffi } \\
\text { Campos \& Kellner, } 1985\end{array}$ & type-species & $\begin{array}{l}\text { MN 4805-V (holotype) } \\
\text { Pz-DBAV UERJ } 40\end{array}$ & $\begin{array}{l}\text { Large number (52) of alveoli on the upper } \\
\text { jaw }\end{array}$ \\
\hline $\begin{array}{l}\text { Anhanguera araripensis } \\
\text { (Wellnhofer, 1985) }\end{array}$ & nomen dubium & SNSB-BSPG 1982 I 89 (holotype) & Non diagnostic \\
\hline $\begin{array}{l}\text { Anhanguera santanae } \\
\text { (Wellnhofer, 1985) }\end{array}$ & nomen dubium & SNSB-BSPG 1982 I 90 (holotype) & Non diagnostic \\
\hline $\begin{array}{l}\text { Anhanguera robustus } \\
\text { (Wellnhofer, 1987) }\end{array}$ & nomen dubium & SNSB-BSPG 1987 I 47 (holotype) & Non diagnostic \\
\hline $\begin{array}{l}\text { Anhanguera piscator } \\
\text { Kellner \& Tomida, } 2000\end{array}$ & valid & NSM-PV 19892 (holotype) & $\begin{array}{l}\text { From Kellner \& Tomida (2000): } \\
\text { Middle part of the basisphenoid presents a } \\
\text { constriction; neural spine of the axis forms } \\
\text { a } 45^{\circ} \text { angle; distal articulation of the ulna } \\
\text { bears a sharp ventral crest; shaft of the } \\
\text { scapula is constricted; coracoid has with a } \\
\text { small cranial process; caudal vertebrae are } \\
\text { elongate; neural spines of the middle } \\
\text { caudal vertebrae reach the preceding } \\
\text { vertebra; neural spines of the middle } \\
\text { caudal vertebrae have a well developed } \\
\text { ventral process. }\end{array}$ \\
\hline $\begin{array}{l}\text { Anhanguera spielbergi } \\
\text { (Veldmeijer, 2003) }\end{array}$ & valid & RGM 401880 (holotype) & $\begin{array}{l}\text { From Veldmeijer (2003): mandibular } \\
\text { groove does not extend to the distal lateral } \\
\text { expansion of the mandible; sternal plate } \\
\text { triangular and as long as wide. }\end{array}$ \\
\hline
\end{tabular}




\section{Table 2 (on next page)}

Specimens attributed to Anhanguera

Other specimens of Anhanguera known by complete or almost complete skulls, and which have been described or cited in the literature 
1 Table II. Other specimens of Anhanguera known by complete or almost complete skulls, and which have been described or cited in 2 the literature.

\begin{tabular}{|l|l|l|}
\hline Specimen & Taxonomic history & Taxonomic status in the present work \\
\hline AMNH 22555 & Referred to “Anhanguera santanae” by Wellnhofer (1991) & Anhanguera sp. \\
\hline MN 4735-V & Referred to “Anhanguera araripensis” by Kellner and Tomida, 2000 & Anhanguera sp. \\
\hline NHMUK R 11978 & none & Anhanguera sp. \\
\hline SAO 16494 & Referred to “Coloborhynchus araripensis” by Veldmeijer et al. (2006) & Anhanguera sp. \\
\hline SMNK PAL 1136 & Referred to Anhanguera by Frey \& Martill (1994) & Anhanguera sp. \\
\hline
\end{tabular}


Figure 1

Location map of the Araripe Basin, northeastern Brazil and simplified stratigraphic chart of the Santana Group.

Levels where pterosaur fossils are found are indicated. Modified from Pinheiro \& Schultz (2012).
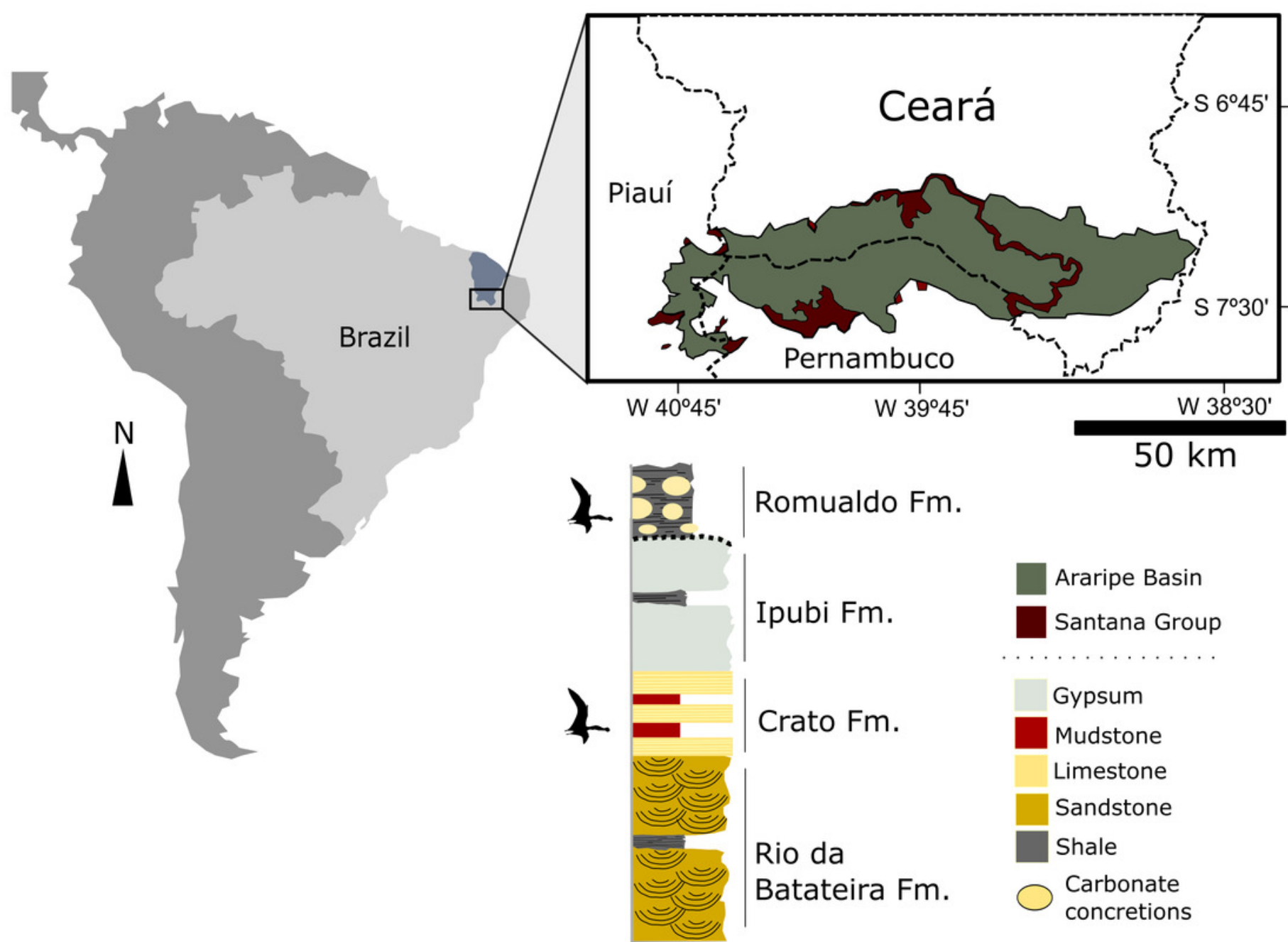
Figure 2

Specimen AMNH 22555, a partial anhanguerid skeleton. Some selected elements are figured in detail.

A, pelvic region in dorsal view; $B$, torso in dorsal view; $C, D$, E, sixth cervical vertebrae in, respectively, anterior, dorsal and right lateral views; F, G, right mandibular ramus in, respectively, medial and lateral views; $\mathrm{H}$, left scapula in dorsal view; I, left coracoid in lateral view; J, distal carpals in distal view; K, proximal carpals in distal view. Scale bars equal to 50 $\mathrm{mm}$. Line drawings of some bones were modified from Witton (2013).

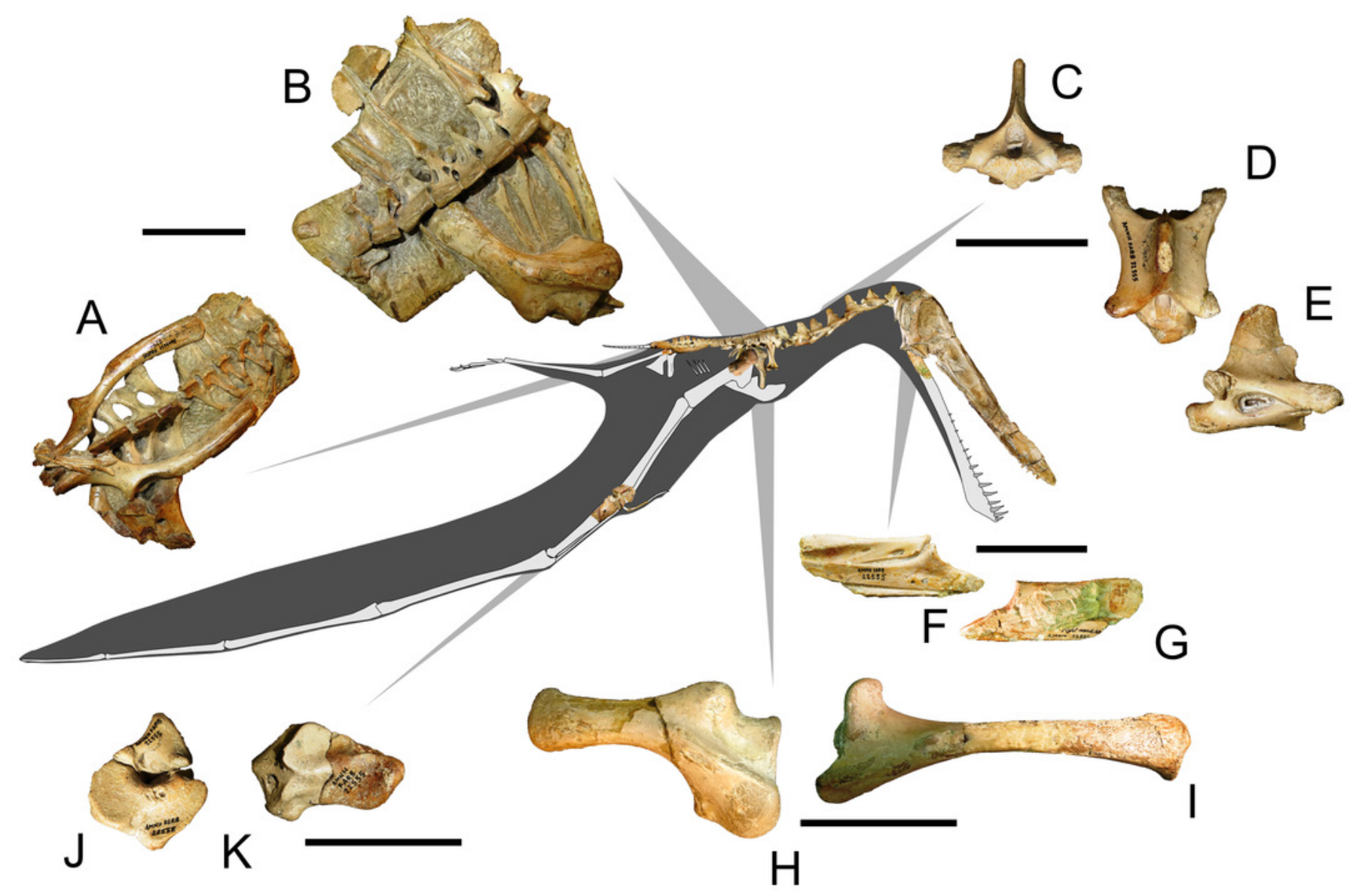


Figure 3

Geometric morphometric analysis of twelve skulls referable to Anhanguera (red dots) and closely related taxa (blue dots) of the regression score on centroid size log.

Used landmarks are plotted in the skull of Anhanguera blittersdorffi holotype.
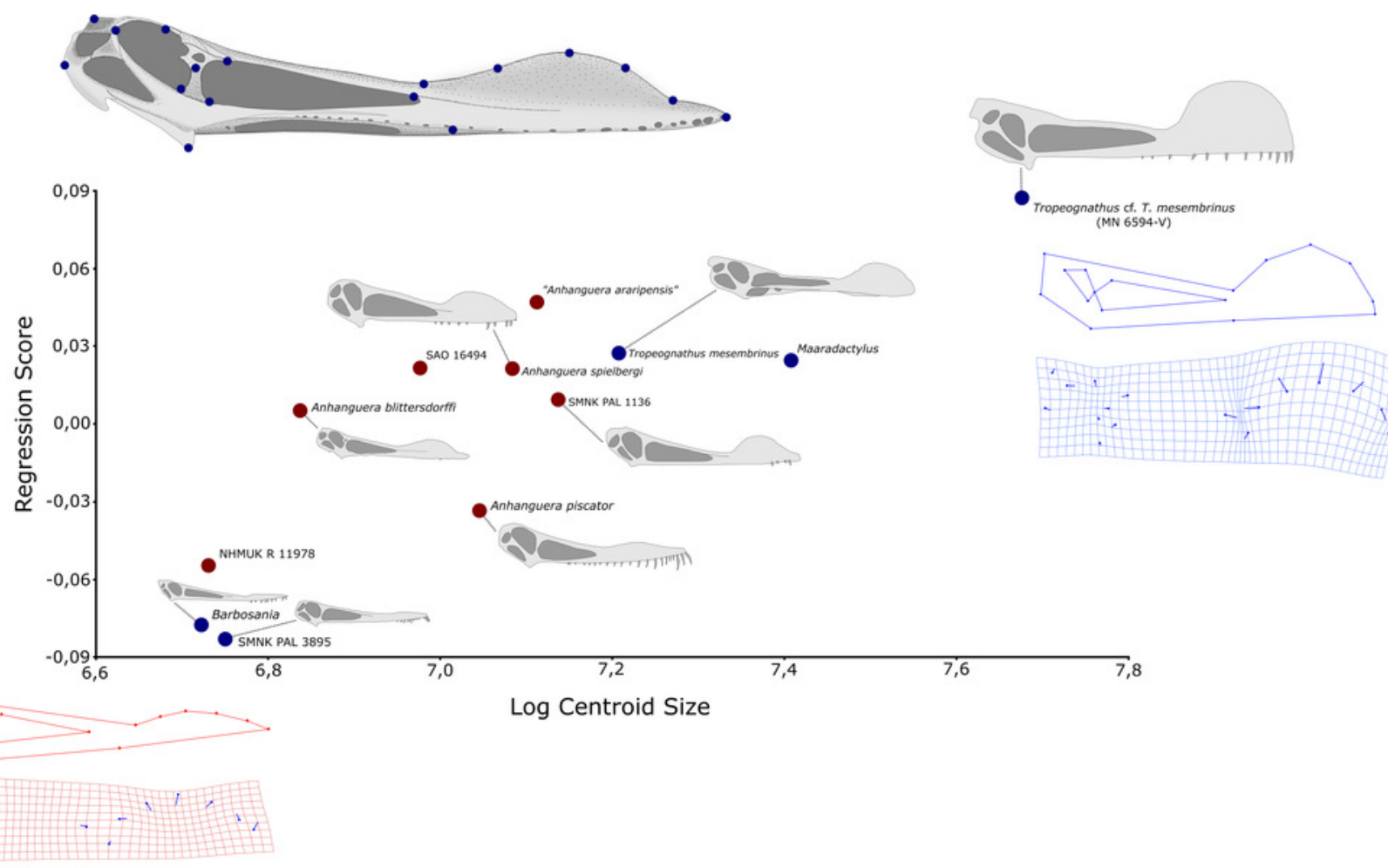

SMink pal 1136

Anhanguera piscator

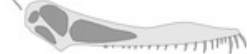

sania

6,8

Log Centroid Size 


\section{Figure 4}

Interpretative drawings of AMNH 22555 skull

A, right lateral, $B$, dorsal and $C$, palatal views. Abbreviations: ch, choanae; fp, frontoparietal; j, jugal; I, lacrimal; m, maxilla; n, nasal; naof, nasoantorbital fenestra; op, opisthotic; pf, prefrontal; po, postorbital; pm, premaxilla; pt, pterygoid; q, quadrate; so, supraorbital; sq, squamosal; v, vomers. Scale bar equals $100 \mathrm{~mm}$.
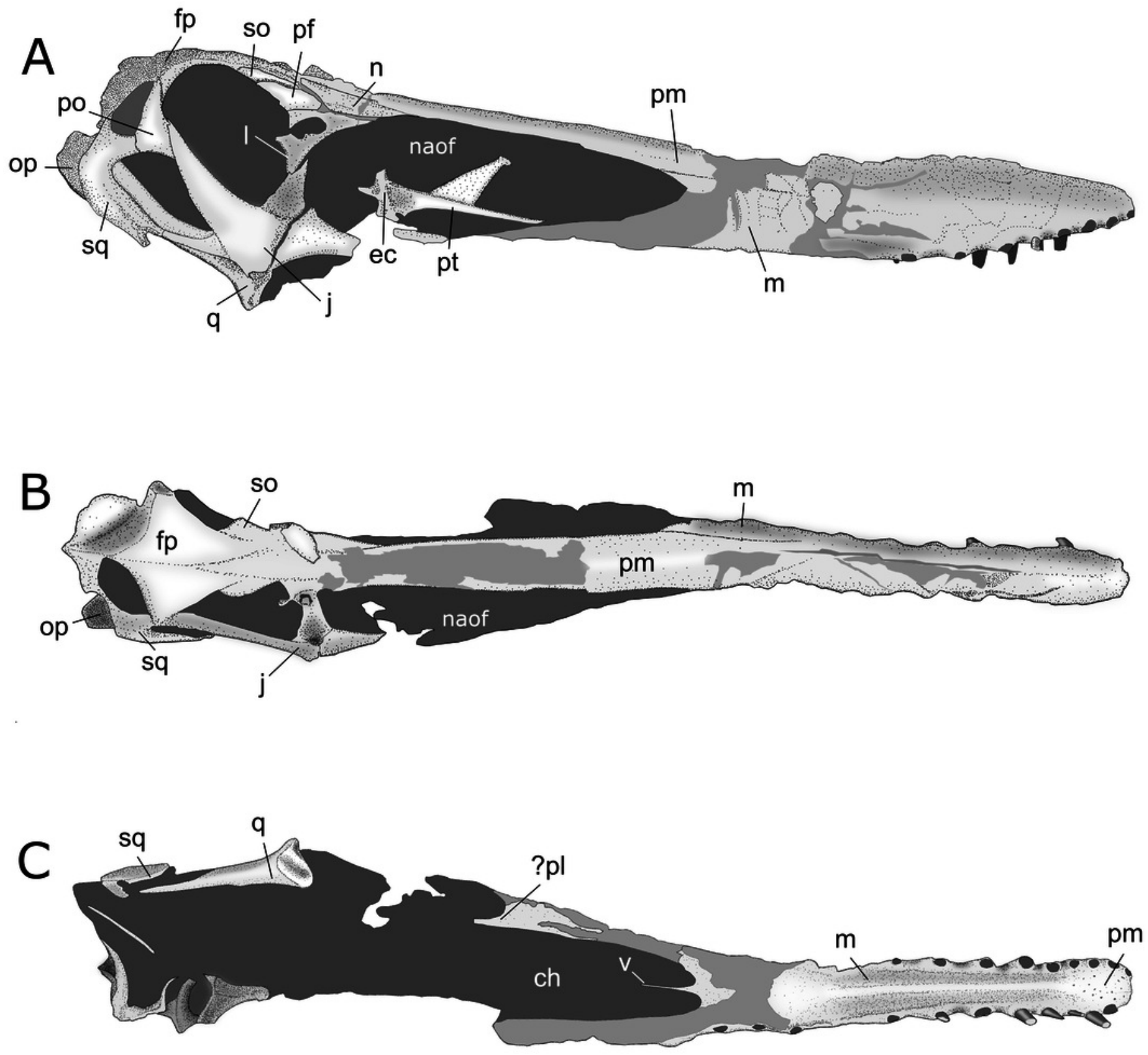


\section{Figure 5}

Comparison between the skulls of AMNH 22555 and Anhanguera santanae holotype (SNSB-BSPG 1982 I 90)

A, AMNH 22555 skull in lateral view; B, Interpretative drawing of the photo in A. C, Anhanguera santanae (SNSB-BSPG 1982 I 90) skull in lateral view (mirrored); ; E, F, G, H, palatal views and interpretative drawings of, respectively, AMNH 22555 and A. santanae (SNSB-BSPG 1982 I 90) skulls; I, J, interpretative drawings of the occipital views of, respectively, AMNH 22555 and A. santanae (SNSB-BSPG 1982 I 90) skulls. Scale bar equal to $100 \mathrm{~mm}$ in $A, B, C, D, E, F, G, H$, and $50 \mathrm{~mm}$ in $\mathrm{I}, \mathrm{J}$.

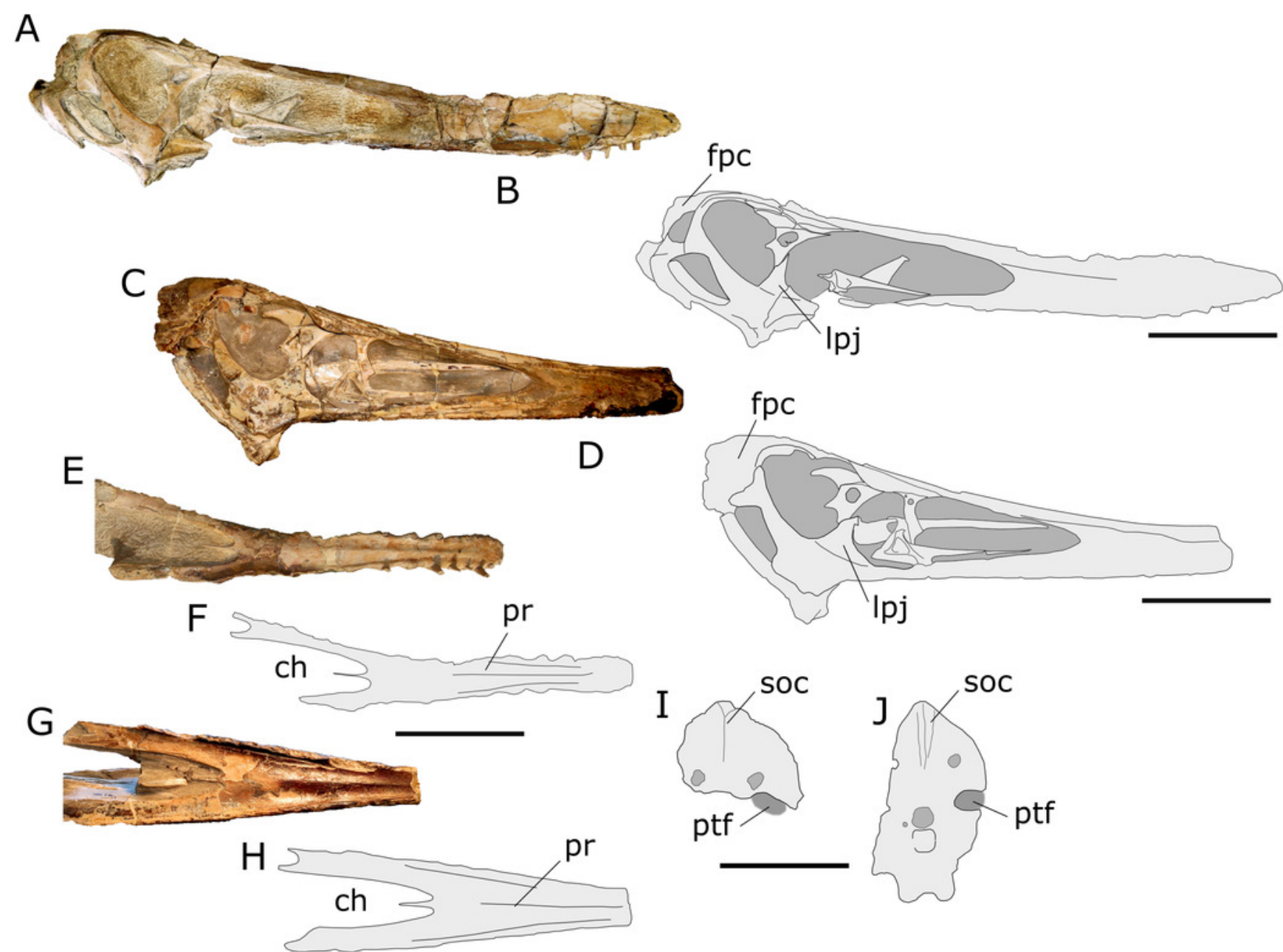




\section{Figure 6}

Overview of the holotypes of several Anhanguera species

A, Anhanguera blittersdorffi (MN 4805-V) in lateral view. B, C, F, "Anhanguera araripensis" (SNSB-BSPG 1982 I 89) in dorsal, ventral, and lateral views, respectively. D, detail of C; arrow points a lateral projection of the pterygoid. $\mathrm{E}$, detail of the Tropeognathus mesembrinus (SNSB-BSPG 1987 I 46); arrow points a bulge laterally on the pterygoid. G, H, holotype of "Anhanguera robustus"( SNSB-BSPG 1987 I 47) in dorsal and lateral views, respectively. I, holotype of Anhanguera spielbergi (RGM 401 880) in lateral view. 


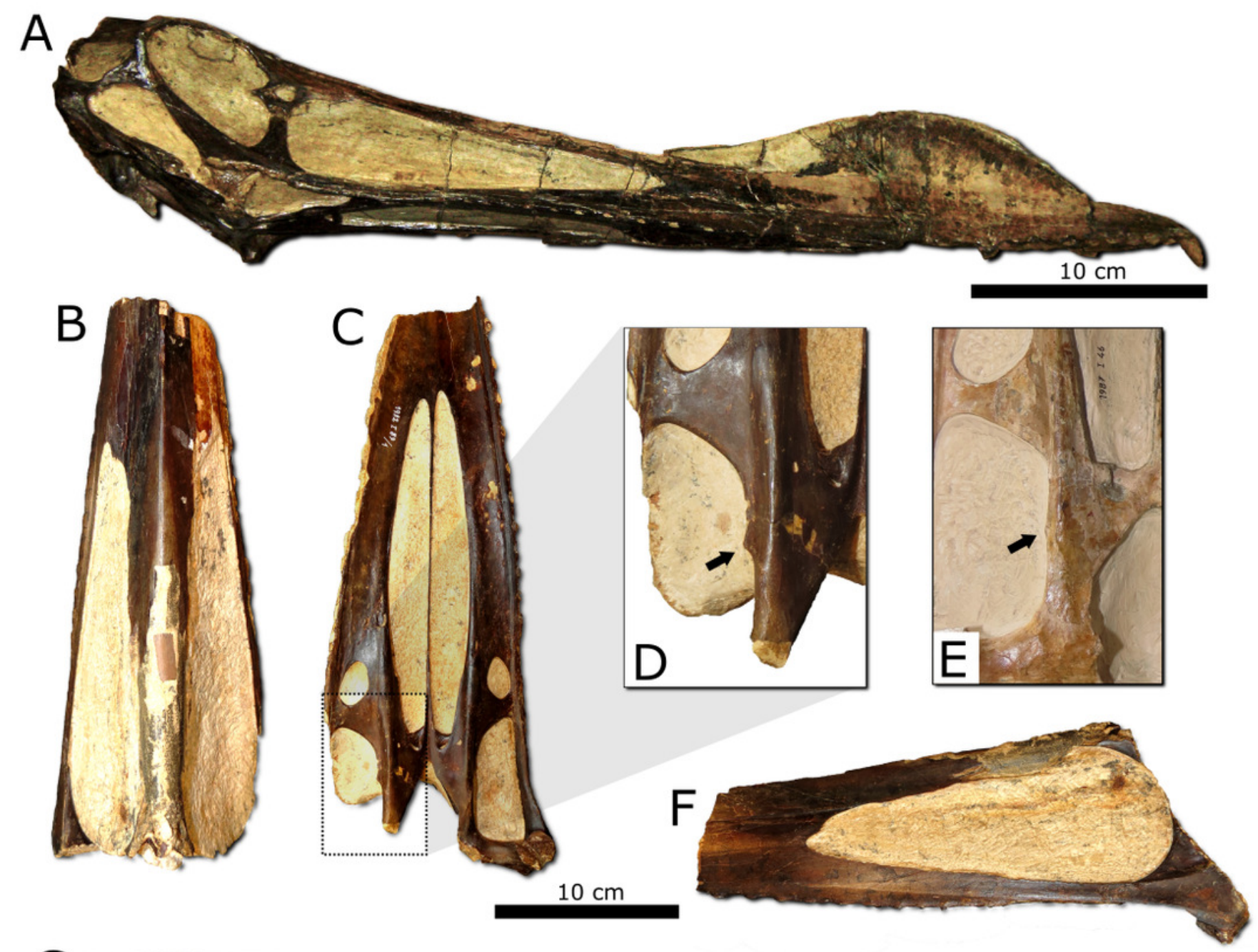

G

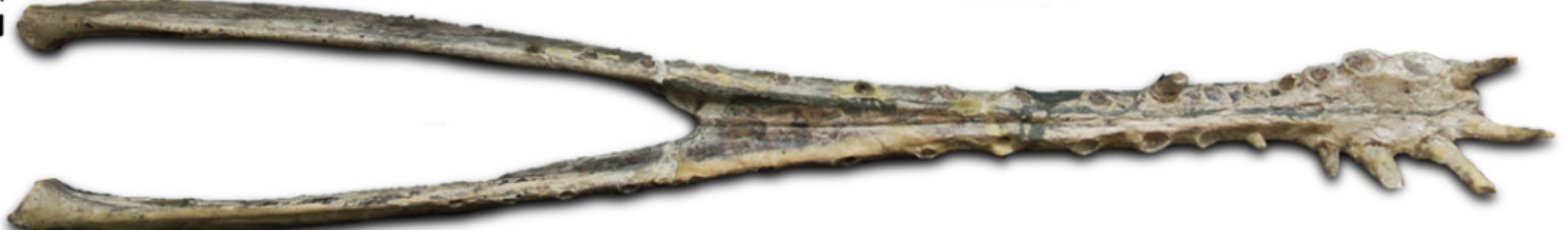

$10 \mathrm{~cm}$

$\mathrm{H}$

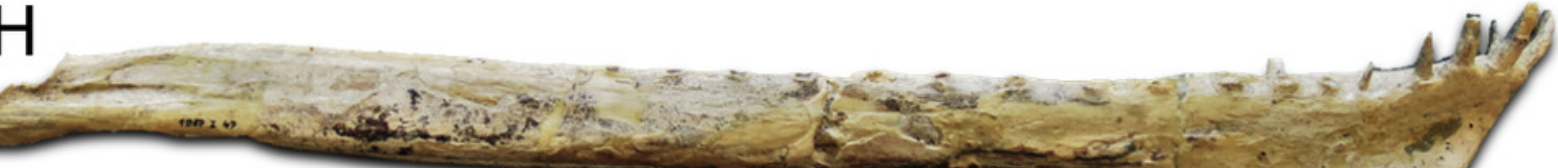

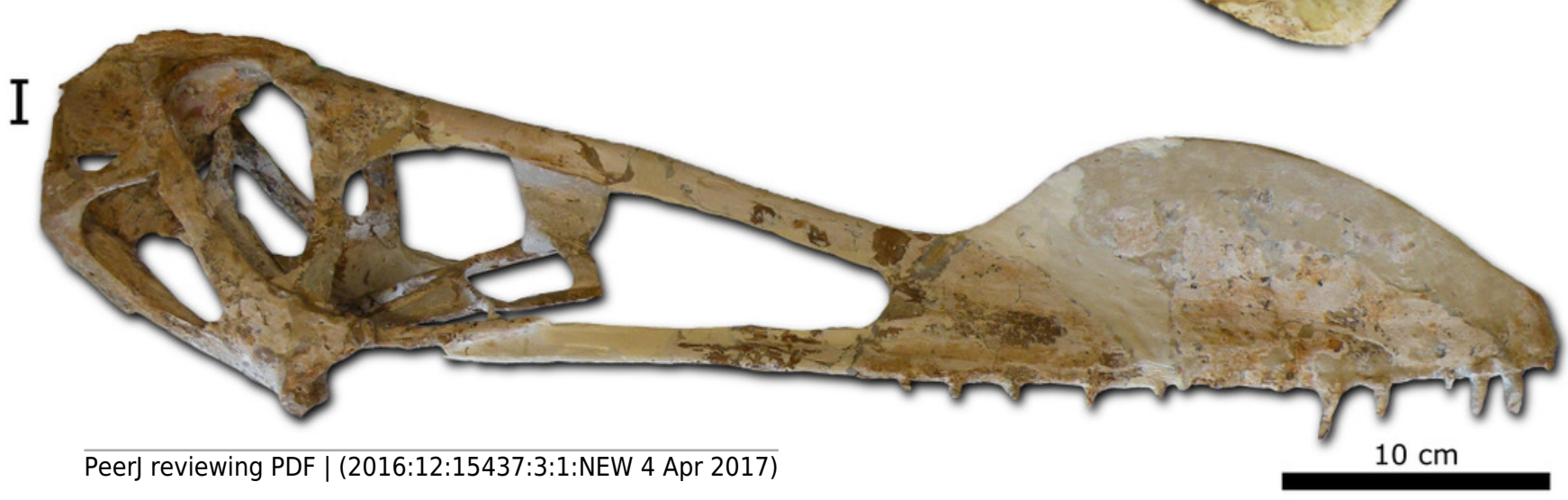

